Discussion Paper No. 782

\title{
TIME DISCOUNTING AND SMOKING BEHAVIOR UNDER TAX HIKES
}

\author{
Myong-II Kang \\ Shinsuke Ikeda
}

June 2010

The Institute of Social and Economic Research

Osaka University

6-1 Mihogaoka, Ibaraki, Osaka 567-0047, Japan 


\title{
Time Discounting and Smoking Behavior under Tax Hikes
}

\author{
Myong-Il Kang ${ }^{1}$ and Shinsuke Ikeda ${ }^{2}$ \\ Korea University \\ ISER, Osaka University
}

June 17,2010

\footnotetext{
* Our special thanks go to Y. Fukuta, M. Nakagawa, F. Ohtake, J. Wan, and participants at the International Workshop on the Economics of Obesity and Health 2009 and the 69th International Atlantic Economic Conference 2010 for helpful comments. We acknowledge financial supports from: the COE and Global COE Programs of Osaka University; a Grant-in-Aid for Scientific Research (B 21330046) from the Japan Society for the Promotion of Science; and the Joint Usage/ Research Center Projects.

${ }^{1}$ Corresponding author: M. Kang, Department of Business Administration, Korea University, 1-700 Ogawa-cho Kodaira, Tokyo 187-8560, Japan. Tel.: 81-42-341-1331. E-mail: 〈mkang@korea-u.ac.jp> 2 S. Ikeda, The Institute of Social and Economic Research, Osaka University, 6-1 Mihogaoka, Ibaraki, Osaka 560-0047, Japan. Tel.: 81-6-6879-8568. E-mail: <Ikeda@iser.osaka-u.ac.jp>
} 


\begin{abstract}
By combining our broad panel survey of Japanese adults from 2005 to 2008 and actual cigarette tax data, we investigate how smoking behavior including responses to tax hikes depends on time discounting and its biases, such as hyperbolic discounting and the sign effect. Cigarette consumption displays significantly positive correlations with discount rates and the procrastinating tendency, and negative correlations with the sign effect. Hyperbolic, procrastinating, and naïve respondents decrease their after-tax-hike cigarette consumption more than the others, implying that, irrespective of the preannouncement of a future tax hike, they postpone smoking moderation until the tax hike actually takes place. Finally, the government's revenue from cigarette tax peaks at a JPY 29.92 (around USD 0.28 using the conversion rate [107.16] in February 2008) higher tax per cigarette than the present actual level.
\end{abstract}

Keywords: smoking, cigarette tax, time preference, discount rate, hyperbolic discounting, procrastination, the sign effect

JEL classification: I18, Z00 


\section{Introduction}

By analyzing our broad survey of Japanese adults from 2005 to 2008, the purpose of this paper is to examine empirically the effects of time discounting and its behavioral biases on smoking behavior, and their responses to a hike in cigarette taxes. We incorporate two time discounting biases that has been reported in dynamic choice theory: (i) hyperbolic discounting, under which a person discounts the immediate future more intensively than the distant future, and thereby makes time-inconsistent decisions; and (ii) the sign effect, by which a person discounts positive future payoffs more intensively than negative future payoffs (for the empirical validity of the biases and their implications, see, e.g., Thaler, 1981; Benzion et al., 1989; Prelec and Loewenstein, 1991; Ainslie, 1992; Khwaja et al., 2007). We hypothesize that hyperbolic discounters smoke more than exponential discounters; that reductions in cigarette consumption after a tax hike amongst naïve hyperbolic smokers are larger than those amongst the others; and that decreases in cigarette consumption after a tax hike amongst hyperbolic smokers are larger than those amongst exponential smokers.

The novelty of the present research is in the following two points. First, we identify respondents' types by whether discounting is exponential or hyperbolic and by whether decision making is sophisticated or naïve. We estimate differences in smoking behavior among the distinct types of respondents. Second, by using the actual time series data of the cigarette tax, which is exogenously determined by the Japan's government, we quantify how the natural experiment of cigarette tax hikes in 2006 affects smoking behavior of each type of respondents. To do so, we use our four-year panel survey data, in which roughly three to five thousands of Japanese adults each year reply to questionnaires on preferences and various attributes.

The main results of this article are as follows: Firstly, discount rates and time discounting biases relate to cigarette consumption. Discount rates, the procrastinating tendency, and naiveness have significantly positive associations with cigarette consumption and the sign effect has significantly negative correlations to smoking behavior. Secondly, tax hikes decrease ex-post smoking. In particular, hyperbolic, procrastinating, or naïve respondents decrease their after-tax-hike cigarette consumption more than others, 
implying that they postpone smoking moderation in response to future tax hikes and thereby adjust cigarette consumption mainly after the tax hike. Thirdly, other factors, e.g., gender, degree of risk aversion, education, household income, age, and existence of children significantly relate to smoking behavior. Finally, the government's revenue from cigarette tax peaks at a JPY 29.92 (around USD 0.28 using the conversion rate [107.16] in February 2008) higher tax per cigarette than the present actual level.

In the present research, we follow Ikeda et al. (2010) in constructing data for discount rates, hyperbolic discounting or procrastination, and the sign effect from response data to questions on various hypothetical intertemporal decisions including choices between a small amount of present money and a larger amount of future money. In addition, naïve and sophisticated respondents are identified by using response data to two questions regarding procrastination in doing homework assignments: one regarding when they used to plan to do homework in summer vacations in their school days; and the other regarding when they in effect used to do homework. Respondents are classified as naïve if they used to procrastinate doing homework more than they planned whereas they are classified as sophisticated otherwise.

There are many empirical studies which investigate smoking behavior from the viewpoint of intertemporal decision makings (e.g., Mitchell, 1999; Bickel et al., 1999; Odum et al., 2002; Baker et al., 2003; Sato and Ohkusa, 2003; Reynolds et al., 2004; Ohmura et al., 2005; Khwaja et al., 2007; Ida and Goto, 2009) and by using rational addiction models (e.g., Chaloupka, 1990, 1991; Keeler et al., 1993; Becker et al., 1994; Bardsley and Olekalns, 1998; Luo et al., 2003; Wan, 2006). Despite many attempts, however, the existing literature has not incorporated the effects of time discounting biases that behavioral economics has been reporting as important determinants of seemingly irrational behaviors such as time-inconsistent impulsive consumption of drugs and cigarettes (see, e.g., Ainslie, 1992).

Our research is closely related in spirit to Gruber and Koszegi (2001), which quantified by calibrations the welfare-enhancing effects of cigarette taxation under hyperbolic discounting. Although they emphasized the critical role that time-inconsistent preferences played in smoking-decision making, for their result to be empirically valid, it should be empirically examined how hyperbolic discounting affects smoking behavior, including responses to tax hikes, and how cigarette consumption differs between naïve and sophisticated smokers. ${ }^{1}$

\footnotetext{
${ }^{1}$ In pararel with our research, Ida (2009) examines correlations between implusiveness (hyperbolic
} 
The remainder of the paper is structured as follows: in section 2, our hypotheses of relations between time preferences and smoking are discussed. Section 3 presents a description of the data. Section 4 reports the estimation results about the determinants of smoking. Section 5 shows the differences of responses to tax hikes among types of time discounting and presents the policy implications of tax hikes. Finally, section 6 concludes the paper.

\section{Time discounting and smoking}

\subsection{Discount rates}

As shown by the theory of rational addiction (Becker and Murphy, 1988), persons with high discount rates can raise present utility by consuming addictive goods even if it induces future disutility by accumulating addiction, and thus they would smoke more than others. Indeed, significantly positive correlations between the amount of smoking and discount rates has been reported in literature (e.g., Bickel et al., 1999; Mitchell, 1999; Odum et al., 2002; Baker et al., 2003; Sato and Ohkusa, 2003; Reynolds et al., 2004; Ohmura et al., 2005; Ida and Goto, 2009). Therefore, it can be hypothesized that persons with higher discount rates tend to smoke more than others.

\subsection{Hyperbolic discounting}

Hyperbolic discounting, under which a person discounts the immediate future more intensively than the distant future, induces the present bias, and thereby likely lead consumers to smoke excessively by underweighting the resulting future disutility. Sophisticated hyperbolic discounters, who are well aware of their procrastinating tendency due to hyperbolic discounting, smoke time-consistently by choosing

discounting) and smoking by eliciting discount rates and risk preferences simultaneously from cross-section data. He does not distinguish sophisticated and naïve respondents, incorporate sign effects, nor analyze the effect of tax hikes. 
sequences of such high cigarette consumption levels that future selves would also choose under the same present bias. On the other hand, naïve hyperbolic discounters, who are unaware of their hyperbolic discounting, do not take into account their time-inconsistency problem in the smoking decision and therefore, smoke more than the sophisticated.

From the same logic, when the cigarette tax rises, hyperbolic discounters are likely to reduce cigarette consumption later than exponential discounters. Insofar as hyperbolic discounters are forward-looking optimizers, they start decreasing cigarette consumption when the preannouncement of a future tax hike takes place. Sophisticated hyperbolic discounters, however, choose such a small decrease in earlier period that future selves can consistently support. It is only after the tax and hence the cigarette price actually rises when they decrease cigarette consumption largely. In sum, sophisticated hyperbolic discounters procrastinate to moderate cigarette consumption until the tax hike is actually introduced. Naïve hyperbolic discounters procrastinate time-inconsistently the moderation of the consumption with a high discount rate for immediate future disutility. Thus, we hypothesize that hyperbolic discounters tend to smoke more than exponential discounters, and that even when a tax hike is pre-announced, they are likely to moderate cigarette consumption substantially after the tax hike is actually implemented. ${ }^{2}$

\subsection{The sign effect}

The sign effect, by which a person discounts positive payoffs more intensively than negative payoffs, leads to moderation in current addictive consumption because future disutility through the harmful effects of addiction is overvalued (e.g., Baker et al., 2003). Therefore, we hypothesize that person with the sign

\footnotetext{
${ }^{2}$ In the context of rational addiction, hyperbolic agents behave forward-lookingly take into account future utility/disutility of addictive consumption (Gruber and Koszegi, 2002). However, it is difficult to analytically show whether hyperbolic discounters genarally smoke more than exponential discounters. Laibson $(1997,1998)$ shows that, under certain conditions, the effective discount rate which is obtained by transforming the hyperbolic discounting function into the exponential one is greater than the pure exponential discount rate. Accordingly, we hypothesize that persons with hyperbolic discounting or procrastination tend to smoke more than ones with exponential discounting.
} 
effect smoke less than others.

\section{The data}

Our empirical research is based on the annual panel data of the Japan Household Panel Survey on Consumer Preferences and Satisfaction (hereafter, JHPS) from 2005 to 2008. Table1 summarizes the number of samples and respondents. The JHPS was set up in 2004 as a project of the COE program in Osaka University using a random sample by a placement method and it had 4,224 respondents in 2004 and 2,987 in 2005. Excluding 108 individuals lost from the respondents in 2005, 2,000 new random-sampled individuals were added to the survey sample, and 3,763 individuals responded in 2006 and 3,112 in 2007. The number of respondents was 4,018 in 2008, with 2,731 being continuous respondents from the previous year and 1,287 mailing their poll responses. All surveys were conducted in February, except in 2006 when the survey was conducted in February and March.

Insert Table 1:

The number of samples and frequencies of responses

\subsection{Tax hikes and cigarette consumption}

\subsubsection{Cigarette consumption}

The JHPS asks respondents about their smoking habits saying, "How many cigarettes do you smoke regularly? Select a proximal option from the following; (i) Never smoke at all; (ii) Hardly smoke; (iii) Smoke sometimes; (iv) About 10 cigarettes a day; (v) About a pack a day; (vi) More than 2 packs a day." In 2007 and 2008, option “(vii) I used to smoke but have quit” is added.

To quantify cigarette consumption, we categorize respondents who select option (i), (ii) or (vii) as nonsmokers, (iii) as smokers consuming 0 to 5 cigarettes a day, (iv) 5 to 15 , (v) 15 to 40 , and (vi) as more 
than 40. By using the category data, we apply the method developed by Kimball et al. (2005) to estimate a $\log$ normal distribution for the distribution of the respondents' cigarette consumption of each year, from which each respondent's cigarette consumption is estimated as an expected value conditional on his or her categorical level of smoking.

Insert Table 2:

Summary statistics of smoking behavior

Insert Figure 1:

Transition graphs of smoking behavior

The summary statistics of cigarette consumption and smoking rates are shown in Table 2 and the transition graphs are described in Figure 1, where SMOKING represents the cigarette consumption estimated above. Male smokers smoke more than a pack per day and the amounts of smoking and smoking rates decreased during the entire investigation. On the other hand, the reported smoking amounts for females are around 15 per day and the amounts increased over time from 2005 to 2007 and decreased in 2008, although their smoking rates decrease throughout the entire period. These trends are consistent with the reported data of the National Survey of Health and Nutrition (NSHN) conducted by the Ministry of Health, Labour and Welfare, Japan: According to NSHN data from 2004 to 2005, the smoking amounts for male smokers decreased from 21.5 to 21.0 per day and the rates of regular smoking declined from $43.3 \%$ to $39.3 \%$. As for females, smoking amounts increased from 14.6 to 15.6 per day and their rates of regular smoking decreased from $12.0 \%$ to $11.3 \%$.

\subsubsection{Tax hikes}

We can examine the effect of the tax hike on smoking behavior because a change of taxation policy on cigarettes arose during our sample period. The Japanese Government raised the cigarette tax from JPY 7.892 (around USD 0.074 using the conversion rate [107.16] in February 2008) to JPY 8.744 (around USD 
0.082) per cigarette on July 1st, $2006 .^{3}$ Our survey in 2006 was conducted in February, which is after the Cabinet meeting on January 17th adopted the outline of revisions in the taxation system, and before the Diet on March 27th that passed the bill.

Our data are not frequent enough to detect the preannouncement effect of tax hikes unlike in Becker $e t$ al. (1994) which use monthly data. Therefore we limit our attention to smoking moderation after the tax hikes. ${ }^{4}$ To examine post-tax hike behavior, we define a tax variable, named TAX, which represents the tax levels in each year.

\subsection{Eliciting discount rates and its behavioral biases}

In the JHPS, the respondents' discount rates were measured by asking five questions about intertemporal choice under alternative conditions. As in the previous survey research (e.g., Harrison et al., 2002; and Borghans and Golsteyn, 2006), the respondents were told to choose a preferable option from two options “A" and "B," e.g., "A" receiving JPY 10,000 (around USD 93.32) in two days; and "B" receiving JPY 10,000 plus a certain amount of JPY $\alpha$, say JPY 10,038 (around USD 93.67), in nine days, where choosing the delayed receipt " $\mathrm{B}$ " instead of "A" implies receiving $20 \%$ of the annual interest rate. In each question, eight such problems were posed in the form of a payoff table, with alternative $\alpha$ values, from small to large, and hence with alternative imputed interest rates, from low to high.

Table 3 shows QUESTION 1, where the amount of receipt for option "A" is specified as JPY 10,000 and the imputed interest rate for option "B" changes from $-10 \%$ to $300 \%$. Respondents are expected to choose option "A" at low interest rates whereas, as the imputed interest rate goes up, to switch to "B" at some critical high rate. The individual respondents' discount rates can be inferred by estimating the interest rate at which the delayed receipt of " $\mathrm{B}$ " is indifferent to the more immediate receipt of "A". The elicited discount rates are associated with the particular choice conditions, e.g., two days vs. nine days, JPY 10,000

\footnotetext{
${ }^{3}$ The price of Mild Seven Super Lights, which has hold the largest share of the Japanese market, has been risen from JPY 270 (around USD 2.52) per 20-cigarette pack to JPY 300 (around USD 2.80) following the tax hike.

${ }^{4}$ Announcement of the Cabinet approval for the still unpassed bill is weak as information about the tax hike, and the date when our survey was conducted, Feb., 2006, is far from the execution date, Jul. 1st, 2006.
} 
for option "A" in QUESTION 1.

Insert Table 3:

Question to elicit discount rates: An example (QUESTION 1 for $\mathrm{DR}_{1}$ )

To test for time discounting biases, five questions were designed by controlling for: (i) money amounts for option "A" as JPY 10,000 or JPY 1 million (around USD 9331.84); (ii) time horizons for "A" as two days, one month, or ninety days; (iii) time delays as seven days or 12 months; and (iv) receipt or payment. In "payment" question 5, the respondents were asked to choose: "A" paying JPY 1 million in one month; or "B" paying JPY 1 million plus some amount in 13 months, from which acceptable interest rate payments to delay a JPY 1 million payment for 12 months were measured.

From each question, we obtaine raw response data in the form of category numbers, which tell us between which interest rates each respondent's choice switched from option " $\mathrm{A}$ " to " $\mathrm{B}$ " if any switch takes place. Some subjects did not switch their choices from "A" for all offered interest rates. By using the raw category data, we apply the method developed by Kimball et al. (2005) to estimate a log normal distribution for the cross-respondent distribution of gross discount rates, from which each respondent's gross discount rate for a certain question, i.e., a certain payoff table, is estimated as an expected value conditional on his or her switch taking place at a certain observed category. Descriptive statistics of elicited discount rates, together with the choice conditions under which they were elicited, are summarized in Table 4, where $D R_{i}(i=1, \cdots, 5)$ represents the discount rate estimated from question i.

\section{Insert Table 4:}

Elicited discount rates under alternative choice conditions

To test for the effect of impatience on cigarette consumption, we construct DISCRATE, which represents the simple average of the standardized values of the elicited discount rates $D R_{i, t}(i=1, \cdots, 5$, $t=2005, \cdots, 2008)$ 


$$
\operatorname{DISCRATE}_{t}=(1 / 5) \sum_{i=1}^{5}\left[\left(D R_{i, t}-E_{t}\left(D R_{i, t}\right)\right) / \sigma_{t}\left(D R_{i, t}\right)\right]
$$

where $E_{t}\left(D R_{i, t}\right)$ and $\sigma_{t}\left(D R_{i, t}\right)$ represent sample means and standard deviations of $D R_{i, t}$ (see table 4). It is hypothesized that, with other things being equal, the respondents' cigarette consumption depends positively on the impatience index DISCRATE.

Table 5 shows the simple correlation of time discounting variables with SMOKING.. Consistent with our hypothesis mentioned above, column 1 shows a significantly positive correlation betwwwn DISCRATE and cigarette consumption. ${ }^{5}$

\section{Insert Table 5:}

Correlation coefficients of time discounting variables with SMOKING

Table 6 summarizes the definitions, summary statistics of variables and hypothesized signs of variables that are used in the analysis below. ${ }^{6}$

\section{Insert Table 6:}

Definitions, summary statistics, and hypothesized signs of variables

\subsubsection{Time discounting biases}

By comparing the mean values of the elicited discount rates, we examine whether our average respondent displays the aforementioned two biases of time discounting. First, in any years, hyperbolic discounting or the immediacy effect is not observed on average since the mean of discount rate $\mathrm{DR}_{1}$, imputed from the

\footnotetext{
${ }^{5}$ More detailed correlation coefficients by gender in each year are summarized in Appendix B.

${ }^{6}$ Although the standardized average DISCRATE of the elicited discount rates should theoretically satisfy

$\mathrm{E}(\mathrm{DISCRATE})=0$ and $\sigma(\mathrm{DISCRATE})=1$, neither equality is actually met as seen in the table. This comes from the fact that the numbers of effective responses differ among the five discount rate questions.

${ }^{7}$ More detailed statistics by gender in each year are summarized in appendix A and C.
} 
immediate future choice (i.e., 2 days or 9 days), is not significantly higher than $\mathrm{DR}_{2}$, applied to more distant future choice (i.e., 90 days or 97 days). Secondly, in all years, the discount rate $\mathrm{DR}_{4}$ applied for future receipts is significantly higher than $\mathrm{DR} \square$, the one used to discount future payments, which implies that our average respondent displays the sign effect ${ }^{8}$

To examine the effects of the time discounting biases on the respondents' cigarette consumption, we construct a binary indicator HYPERBOL for hyperbolic discounting and SIGN for the sign effect, where, e.g., HYPERBOL $=1$ if $\mathrm{DR}_{1}>\mathrm{DR}_{2}$ and $\mathrm{HYPERBOL}=0$ otherwise. From the mean values of $\mathrm{HYPERBOL}$ and SIGN, shown in Table 5, the proportions of the respondents who display the anomalies are $67.3 \%$ for hyperbolic discounting and $90.3 \%$ for the sign effect. Our hypothesis is that, with other things being equal, the respondents' cigarette consumption is positively related to HYPERBOL and negatively to SIGN.

In Table 5, the correlation coefficient of SIGN with cigarette consumption is significantly positive as expected above. The coefficient of HYPERBOL is, however, negative, which is inconsistent with our hypothesis. In section 4, we will discuss whether these results are robust after controlling other factors.

\subsubsection{A proxy for procrastination and naïve hyperbolic discounting}

To capture the immediacy effect, we also construct a proxy variable PROCR for hyperbolic discounting and NAÏVE for naïve agent. To measure respondents' degrees of hyperbolic discounting or procrastination, the JHPS survey asked them to indicate on a 5-point scale from 1 to 5 how they had been likely to procrastinate doing homework assignments for the vacation in their childhood. ${ }^{9}$ Variable PROCR is the response data to this question averaged over time, where a larger value implies a stronger tendency for

\footnotetext{
${ }^{8}$ In addition, although we have not put the results of the $t$ test in the table, $\mathrm{DR}_{3}$, the discount rate for JPY 10,000 (around USD 93.32), is significantly higher than DR 4 , which applies for JPY 1 million (around USD 9331.84). This implies that people are more patient for larger amounts than for smaller amounts. This tendency is called the magnitude effect (e.g., Benzion et al., 1989; Frederick et al., 2002).

${ }^{9}$ In Japanese elementary and high schools, students are usually assigned many pieces of homework during summer vacations.
} 
procrastination or hyperbolic discounting. The JHPS survey also asked respondents in 2007 and 2008 how they had projected doing homework assignments for the vacation in their childhood with the same point scales as above. We define differences in PROCR from the response to this question and average them over time as NAÏVE, which indicates the degree of default in own planning. It is hypothesized that, with other things being equal, the respondents' cigarette consumption depends positively on PROCR and NAÏVE. Table 5 shows that PROCR and NAÏVE have strongly positive correlation with smoking as predicted.

Figure 2 shows the distributions of PROCR and NAÏVE. As shown in panel A, the proportion of people who had done their homework assignment latterly, whose PROCR is more than 4, is slightly less than half of the respondents. Meanwhile $67.1 \%$ of all respondents, shown in panel $\mathrm{B}$, had been unable to do their homework assignment when planned.

Insert Figure 2:

Distributions of PROCR and NAÏVE

\subsection{Control variables}

We define the following variables for controlling personal attributes: RISKAV, MALE, UNIV, INCOME, AGE, and CHILD.

RISKAV measures the degree of risk aversion, which is constructed by subtracting from 100 the respondents' responses to the question: "When you go out, how high a probability of rainfall makes you bring an umbrella with you?" We hypothesize that more risk-averse respondents are likely to consume less cigarettes.

MALE is a binary indicator which equals 1 if the respondent is male and 0 if female. As shown in Table 2 and Figure1, average cigarette consumption and smoking rates for males are larger than for females in our Japanese data, and therefore we naturally hypothesize that being male has positive effects on smoking.

UNIV is a proxy variable of respondents' education level, which equals 1 if the respondent had 
received college education and 0 otherwise. It was hypothesized that persons with a college background smoke less than others.

INCOME takes the value of per capita household income in ten thousand yen. Previous studies empirically verify positive relation between income levels and the smoking status (e.g., Hersch, 2000; Ishii, 2005). ${ }^{10}$ According to the literature, we hypothesize that persons earning higher incomes are likely to consume less cigarettes.

AGE takes ages of respondents. Hersch (2000) shows that the effect of age on cigarette consumption displays a nonlinear relation, which is significantly positive for the linear term and negative for the quadratic term. Ishii (2005) reports the same relation for japanese female samples. We hypothesize that the effect of AGE on cigarette consumption is positive in the linear term and negative in the quadratic term.

CHILD is a binary indicator that takes 1 if the respondent has children and 0 otherwise. Hersch (2000) reports that females having a youngest child under 2 years old decrease their cigarette consumption. Our hypothesis is that females with children moderate their smoking behavior.

The correlation coefficients between control variables and SMOKING are shown in table $7 .^{11}$

\section{Insert Table 7:}

Correlations between SMOKING and control variables

MALE displays a significantly positive coefficient and RISKAV and UNIV display negative coefficients for all, male, and female samples as expected. The coefficient of INCOME for female samples is significantly negative as hypothesized. On the other hand, for all and male samples, the coefficients of INCOME are insignificant, which is consistent with Ishii (2005).

Coefficients of AGE are negative and strongly significant. These results are seemingly shown as

\footnotetext{
${ }^{10}$ Hersch (2000) reports that high-income groups display lower smoking rates than other groups by using US data. Ishii (2005) shows that, by using Japanese data, logarithmic household income displays a significantly negative correlation with the amount of cigarette consumption for female samples and with smoking rates for male and female samples.

11 More detailed statistics by gender-year are summarized in Appendix D.
} 
contrary evidence for the literature and our hypothesis. As seen in Figure 3, however, which displays graph trends of averaged cigarette consumption of smokers by gender in their 20 s to 70 s, cigarette consumption looks like following quadratic trends. In the next section, we will use the linear and the quadratic terms of AGE as explanatory variables for capturing the age trend of smoking.

Insert Figure 3:

Age trends of averaged cigarette consumption of smokers

As is pointed out in Hersch (2000), for female samples, CHILD displays a significantly negative coefficient, which implies that the presence of children reduces cigarette consumption. ${ }^{12}$

\section{Determinants of smoking behavior}

In this section, we estimate the marginal effects on SMOKING using random-effects tobit models to identify determinants of cigarette consumption. The following three models are estimated: model (1) uses as explanatory variables DISCRATE, HYPERBOL, SIGN, and other control variables including TAX; model (2) adopts PROCR, instead of HYPERBOL, to capture the effect of hyperbolic discounting; and model (3) adopts NAÏVE for hyperbolic discounting. All the models are estimated in all, male and female samples. Table 8 shows the estimation results. All coefficients display the marginal effects which are measured around the mean values of smokers.

Insert Table8:

Random-effects tobit estimations for SMOKING

\footnotetext{
${ }^{12}$ Unreported tests of the differences of the average of cigarette consumption between females with and without children including nonsmokers' samples suggest that the former significantly smoke less than the latter, but using only smokers' samples suggest that having children is insignificant. This implies that having children leads to quitting, rather than reducing, smoking.
} 


\subsection{Tax hikes}

The coefficients of TAX are significantly negative for all and male samples, where hiking per cigarette tax by one yen, ceteris paribus, decreases per capita cigarette consumption by 0.32 (model (3)) to 0.43 (model (2)) in all samples or by 0.49 (model (3)) to 0.60 (model (2)) in male samples. On the other hand, the insignificant coefficients for the female sample suggest that there would be some female-specific factors that push up their smoking in our sample period. Differences in smoking moderation behavior under tax hikes due to the types of time discounting and/or the degree of the biases will be estimated in the next section.

\subsection{Time discounting}

In model (1), consistent with our hypothesis, DISCRATE displays positive effects on cigarette consumption, which are, significant for all and female samples. The sign effect SIGN has expected negative coefficients, which are significant for all and male samples. In contrast, the results regarding the coefficients of HYPERBOL are weak. In particular, they are insignificantly negative for all and male samples.

In model (2) and model (3), all of DISCRATE, PROCR and NAÏVE display fairly significant coefficients with the expected sign. Especially, all of them have strongly significant coefficients in the all sample case. Male samples also display significant effects of these variables, and for female samples all coefficients of time discounting variables except for the sign effect of model (2) are significant. All of them are consistent with our expectations.

In sum, cigarette consumption has expected correlations with discount rates, procrastination, naiveness, and the sign effect. Discount rates, for example, that exceed the average by one unit of standard deviation, ceteris paribus, increase the amount of cigarette consumption by 0.32 (model (2)) to 0.34 (model (3)) for males and by 0.20 (model (3)) to 0.32 (model (1)) for females. The respondents who had procrastinated about doing their homework until the very end of the vacation $(\mathrm{PROCR}=5)$, ceteris paribus, smoke more than respondents who had finished it at the beginning of the vacation (PROCR=1) by 1.096 for males and 
by 0.528 for females. The most naïve respondents $(\mathrm{NAIIVE}=4)$ smoke more than sophisticated ones (NAÏVE=0) by 0.874 for males and by 0.539 for females. The respondents with the sign effect (SIGN=1) consume less cigarettes than others, around 0.5 for males and 0.3-0.4 for females.

\subsection{Control variables}

Estimated coefficients of risk aversion variables (RISKAV) display expectedly negative signs, which are strongly significant for all and female samples in all the models. For example, cigarette consumption for female respondents who are risk averse such that their critical precipitation percentage to bring an umbrella is $10 \%$ higher than the average is ceteris paribus lower than the average female by 0.13 (model (3)) to 0.14 (model (1) and (2)). The coefficients of MALE display significantly positive implying that male respondents smoke more heavily than female ones by 5.21 (model (3)) to 5.71 (model (1)). Coefficients of UNIV are strongly significant consistent with our expectations for all, male, and female in the entire models. Respondents with a college background smoke less than others by 0.91 (model (3)) to 1.41 (model (2)) for males and by 1.43 (model (3)) to 1.48 (model (1)) for females. Smoking depend significantly on AGE in a quadratic form in the entire models, such that cigarette consumption increase with aging at decreasing rates until some critical age, and thereafter it decreases at increasing rates. The critical peaks of smoking are an age of 39.89 (i.e., 0.164/2*0.002) years (model (1)), 41.97 (model (2)) and 39.96(model (3)) for male smokers and 38.32 (model (1)), 38.37 (model (2)) and 40.29 (model (3)) for female smokers (after controlling other personal attributes). The estimated signs are consistent with our hypothesis, and the peak ages for cigarette consumption are more or less the same by gender with other things being equal. The coefficients of per capita household income (INCOME) are significantly negative and those of the income squared (INCOME^2) are significantly positive only for female samples in the entire models. The critical income levels of females at the bottom of cigarette consumption are 7.04 (model (1)), 7.04 (model (2)), and 7.03 million yen (model (3)). The coefficients of CHILD are, as are expected, significantly negative for females suggesting that female respondents with children smoke less than others by 0.91 (model (3)) to $0.94(\operatorname{model}(1))$. 


\section{The effects of tax hikes}

In this section, we analyze the effects of time discounting biases on the reduction of cigarette consumption responding to the hiking of cigarette tax. To do so, we sort the sample from the viewpoints of hyperbolic discounting, the procrastinating tendency, and naïveness, and thereby compare the estimated coefficients of TAX among the sorted samples. Our hypothesis is that cigarette consumption of hyperbolic discounting, procrastination, or naïve agents respond more negatively to tax hikes than other samples.

\subsection{Responses to tax hikes with/without hyperbolic discounting}

To detect the effect of hyperbolic discounting, respondents are classified by using HYPERBOL and PROC as follows:

(i) Hyperbolic or exponential: Agents are classified as

- hyperbolic if $\mathrm{HYPERBOL}=1$; and

- exponential if $\mathrm{HYPERBOL}=0$

(ii) The degree of procrastinating tendency is classified as

- severe procrastination if $\mathrm{PROCR} \geqq 5$;

modest procrastination if $5>\mathrm{PROCR} \geqq 3$; and

weak/no procrastination if $\mathrm{PROCR}<3$.

Table 9 shows the marginal effects of tax hikes on cigarette consumption for each type of agents by using random-effects tobit models. All models use SMOKING for dependent variables, and are estimated in all, male and female samples by controlling for DISCRATE, SIGN, RISKAV, MALE, UNIV, AGE, $\mathrm{AGE}^{\wedge}$ 2, INCOME, INCOME^2, and CHILD. The coefficients indicate the marginal effects of TAX.

Panel A of table 9 displays the estimated coefficients of TAX whose samples are sorted by using 
HYPERBOL. For all and male samples, the coefficients of hyperbolic agents (HYPERBOL=1) are significantly negative and the coefficients of exponential agents $(\mathrm{HYPERBOL}=0)$ are insignificant. The differences of the responses to tax hikes between hyperbolic and exponential agents are -0.186 in all samples and -0.442 in the male samples, which are both negative as expected. These results imply that hyperbolic agents reduced cigarette consumption after the tax hike more than exponential discounting agents. For the female samples, the estimated coefficients are insignificant in both agents, however.

Panel B compares the effect of tax reduction on cigarette consumption among different degrees of procrastinating tendency. In the all sample case, the coefficients are significantly negative for respondents with strong and modest procrastination while the coefficient is insignificantly negative for respondents with weak/ no procrastination. The difference of the coefficients between the respondents with strong procrastination and those with weak/ no procrastination is positive as expected. For males, the coefficients for respondents with strong procrastination and with weak/no procrastination are significantly negative, where the difference between the coefficients is negative, consistent with our expectations. For the female sample, although all the coefficients are insignificant, they have expected signs. In sum, hyperbolic or procrastinative agents reduce their cigarette consumption more than exponential agents after tax hikes, which implies that these agents postpone smoking moderation up to after-tax-hike period even though the tax hike was preannounced several months before..

\section{Insert Table 9:}

Comparing the marginal effects of tax hikes for each agent (HYPERBOL and PROCR)

\subsection{Naïve vs. Sophisticated}

We also detect the effect of naiveness by defining the degree of naiveness as follows:

(iii) The degree of naiveness: Respondents are classified as:

- sophisticated if NAÏVE $<1$;

- naïve if $1 \leqq \mathrm{NAÏVE}<4$; and 
- strongly nä̈ve if $\mathrm{NAÏVE}=4$.

By sorting the sample by the degree of naiveness, Table 10 compares the marginal effects of tax hikes on the cigarette consumption, which are estimated in the same manner as table 9 . The values of the estimated coefficients and their differences are consistent with our expectations. In particular, the coefficients for strongly naïve agents in all and female samples and those for naïve agents in all and male samples are significant, where all of the differences exhibit negative signs as expected. These results imply that naïve agents postpone smoking moderation even when a tax hike is pre-announced. It is only after the actual tax hike when they reduce cigarette consumption.

Insert Table 10:

Comparing the marginal effects of tax hikes for each agent (NAÏVE)

\subsection{Policy implications}

Cigarettes are addictive goods which have two important aspects related to policyl decisions: firstly, habitual consumption of them damages health status, and consequently brings about decreases of social welfare and increases of the medical care costs; and secondly the revenues from cigarette taxes are a significant source of public finance. For the governments to decide the cigarette tax level by taking into account both national health care and tax revenues, it is important to estimate the quantitative effects of cigarette tax hikes on smoking behavior and on the resulting tax revenues.

Table 11 shows the estimates of cigarette consumption, the smoking rate, the smoking cessation rate, and the tax revenue after tax hikes, where the three alternative tax hikes are considered: hikes by JPY 10, 20, and 35 (around USD 0.09, 0.19, and 0.33) per cigarette. All results are obtained from the tax elasticity of cigarette demand for smokers, ranging from 0.079 for the heaviest smokers to 1.329 for the lightest smokers. ${ }^{13}$

${ }^{13}$ The elasticity are calculated from the marginal effects of TAX, -0.416 , in model (1) for the all sample, which is measured around the mean values of smokers in 2008. Appendices E and F show the cases of models (2) and 
In 2008, when most cigarettes are priced at JPY 300 (around USD 2.80) per pack, the average cigarette consumption for smokers is 20.87 , and the smoking rate is $25.1 \%$. In the case of a tax hike by JPY 10 (around USD 0.09) per cigarette, which is equivalent to setting the price at JPY 500 (i.e., $300+(10 * 20)$ ) per pack (around USD 4.67 per pack), the predicted average cigarette consumption after the tax hike is 18.9 and the smoking rate becomes $22.4 \%$. Consequently, $10.7 \%$ of smokers reduce their cigarette consumption in response to the tax hike, and the resulting increase in the rate of tax revenue is $73.2 \%$. In the case of a tax hike by JPY 20 (around USD 0.19) per cigarette, which corresponds to pricing at JPY 700 (around USD 6.53) per pack, the smoking rate becomes $22.4 \%$, and the resulting increase in the rate of tax revenue is $107.2 \%$. In the case of hiking tax by JPY 35 (around USD 0.33) per cigarette, which is equivalent to pricing at JPY 1000 (around USD 9.33) per pack, the smoking rate becomes 15.6\%, and the resulting increase in the rate of tax revenue is $107.9 \%$.

Figure 4 depicts the relationship between the amount of the per-cigarette tax hike and the associated increasing rate of the tax revenue. The government revenue reaches a peak when the per-cigarette tax hike equals JPY 29.92 (around USD 0.28), with the corresponding per-pack cigarette price is JPY 898.4 (around USD 8.38). The break-even tax-hike which keeps the tax revenues unchanged is estimated as JPY 58.85 (around USD 0.55). This implies that even though the government sets the per-pack price of cigarettes at JPY 1,477.09 (around USD 13.78), there is a room to raise tax revenues on one hand, and to decrease the domestic smoking rate, on the other hand. ${ }^{14}$

Insert Table 11:

Tax hikes, smoking moderation, and tax revenue

model (3).

${ }^{14}$ On March 24th, the Japanese government has passed a bill on hiking the cigarette tax by JPY 3.5 (around USD 0.03) per cigarette in October 1st, 2010. Following the passage, JT (Japan Tobacco, Inc.), the Japan's monopolistic cigarette manufacturer, has announced the decision to increase cigarette prices to around JPY 410 to 440 (around USD 3.83 to 4.11) per 20-cigarette pack. According to our estimation results, it is predicted that, by executing the tax- and price-increasing policy, smokers would decrease by $10.7 \%$, and that government's revenue would increase by about 20.3 to $28.4 \%$. 
Insert Figure 4:

Tax hikes and the increasing rates of tax revenue

\section{Conclusion}

By using our broad panel survey of Japanese adults, we have found that discount rates and its behavioral biases affect smoking behavior. Respondents' discount rates are higher, or their procrastinating tendency or naiveness is stronger, they are likely to smoke more than others. In the response to cigarette tax hikes, hyperbolic, procrastinating or naïve agents postpone smoking moderation up to after-tax-hike period even though the tax hike was preannounced several months before.

We have also clarified that the Japanese government is able to hike cigarette taxes for increasing tax revenue. The government's tax-rising policy, however, does not necessary lead to consumer's welfare improvement. It causes welfare losses to exponential discounters, whereas it works as a commitment devise for hyperbolic discounters and consequently increases their welfare level. As the further research, we would like to incorporate heterogeneity of discounting function to determine precise welfare-changing processes and the quantities induced by tax-changing policies. 


\section{References}

Ainslie, G., 1992, Picoeconomics, Cambridge, UK: Cambridge University Press.

Ainslie, G., 2001, Breakdown of Will, Cambridge, UK: Cambridge University Press.

Baker, F., M. W. Johnson, and W.K.Bickel, 2003, Delay discounting in current and never-before cigarette smokers: Similarities and differences across commodity, Sign, and Magnitude, Journal of Abnormal Psychology 112, 382-92.

Bardsley, P., and N. Olekalns, 1999, Cigarette and tobacco consumption: Have anti-smoking policies made a difference?, Economic Record 75, 225-240.

Becker, G. S., M. Grossman, and K. M. Murphy, 1994, An empirical analysis of cigarette addiction, American Economic Review 84, 396-418.

Becker, G. S., and K. M. Murphy, 1988, A theory of rational addiction, Journal of Political Economics 96, 675-700.

Benzion, U., A. Rapoport, and J. Yagil, 1989, Discount rates inferred from decisions: An experimental study, Management Science 35, 270-284.

Bickel, W. K., A.L. Odum, and G. J. Madden, 1999, Impulsivity and Cigarette Smoking: Delay Discounting in Current Never, and Ex-smokers, Psychopharmacology 146, 447-454.

Borghans, L., and B. Golsteyn, 2006, Time discounting and the body mass index: Evidence from the Netherlands, Economics and Human Biology 4, 39-61.

Chaloupka, F., 1990, Men, women, and addiction: The case of cigarette smoking, NBER Working Paper 3267.

Chaloupka, F., 1991, Rational addictive behavior and cigarette smoking, Journal of Political Ecocnomy 99, 675-700.

Gruber, J. and B. Koszegi, 2001, Is addiction "rational"?: Theory and evidence, Quarterly Journal of Economics 116, 1261-1303.

Harrison, G. W., M.I. Lau, and M.B. Williams, 2002, Estimating individual discount rates in Denmark: A field experiment, American Economic Review 92, 1606-1617. 
Hersch, J, 2000, Gender, Income Levels, and the Demand for Cigarettes, Journal of Risk and Uncertainty, $21: 2,3,263-282$.

Ida, T., 2009, Anomaly, Impulsivity, and Addiction, Journal of Socio-Economics, forthcoming.

Ida, T. and R. Goto, 2009, Simultaneous measurement of time and risk preferences: Stated preference discrete choice modeling analysis depending on smoking behavior, International Economic Review 50, forthcoming.

Ikeda, S., M. Kang, and F. Ohtake, 2010, Hyperbolic discounting, the sign effect, and the body mass index, Journal of Health Economics, 29, 268-284.

Ishii, K., 2005, Tabacco zei no hikiage ya Kenko zousinhou wa kinnen ni dokomade yukou ka (in Japanese), Keio University Market Quality Research Project (21COE), DP2005-019.

Keeler, T. E., T-W. Hu, P. G. Barnett, and W. G. Manning, 1993, Taxation, regulation, and addiction: A demand function for cigarettes based on time-series evidence, Journal of Health Economics, 12, 1-18.

Khwaja, A., D. Silverman, and F. Sloan, 2007, Time preference, time discounting, and smoking decisions, Journal of Health Economics 26, 927-979.

Kimball, M. S., C. R. Sahm, and M. D. Shapiro, Using survey-based risk tolerance, 2005, ISER Seminar, unpublished.

Laibson, D., 1997, Golden eggs and hyperbolic discounting, Quarterly Journal of Economics 112, 443-477.

Laibson, D., 1998, Life-cycle consumption and hyperbolic discount functions, European Economic Review 42, 861-871.

Luo, F., M. Abdel-Ghany, and I. Ogawa, 2003, Cigarette smoking in Japan: Examination of myopic and rational models of addictive behavior, Journal of Family and Economic Issues 24, 308-317.

Mitchell, S. H., 1999, Measures of impulsivity in cigarette smokers and non-smokers, Psychopharmacology, 146, 455-464.

Odum, A. L., G. J. Madden, and W. K. Bickel, 2002, Discounting of delayed health gains and losses by current, never- and ex-smokers of cigarettes, Nicotine and Tobacco Research 4, 295-303.

Ohmura, Y., T. Takahashi, and N. Kitamura, 2005, Discounting delayed and probabilistic monetary gains and losses by smokers of cigarettes, Psychopharmacology 182, 508-515.

Prelec, D. and G. Loewenstein, 1991, Decision making over time and under uncertainty: a common approach, Management Science 37, 770-786. 
Reynolds, B., K. Karraker, K. Horn, and J. B. Richards, 2004, Delay and probability discounting as related to different stages of adolescent smoking and non-smoking, Behavioural Processes 64, 333-344.

Sato, M., and Y. Ohkusa, 2003, The relationship between smoking initiation and time discounting factor, risk aversion and information, Applied Economics Letters 10, 287-289.

Thaler, R., 1981, Some empirical evidence on dynamic inconsistency, Economics Letters 8, 201-207.

Wan, J., 2006, Cigarette tax revenues and tobacco control in Japan, Applied Economics 33, 1663-1675. 
Table 1: The number of samples and frequencies of responses

\begin{tabular}{l|cccc|c} 
& 2005 & 2006 & 2007 & 2008 & Total \\
\hline Num. of samples & 2,987 & 3,763 & 3,112 & 4,018 & 13,880
\end{tabular}

\begin{tabular}{l|cccc|c} 
& Four times & Three times & Twice & Once & Total \\
\hline Freq. of responses & 1,824 & 1,125 & 488 & 2,233 & 5,670
\end{tabular}

Note: The data are from the Japan Household Panel Survey on Consumer Preferences and Satisfaction from 2005 to 2008. The row of "Num. of samples" shows the number of respondents each year. The row of "Freq. of respondents" shows the number of frequencies in responses during our sample period. 
Table2: Summary statistics of smoking behavior

(Panel A) Cigare tte consumption

\begin{tabular}{rlrrrr}
\hline & & \multicolumn{1}{c}{2005} & \multicolumn{1}{c}{2006} & \multicolumn{1}{c}{2007} & \multicolumn{1}{c}{2008} \\
\hline \multirow{4}{*}{ All } & Mean & 6.502 & 6.226 & 5.873 & 5.238 \\
& S.D. & 11.971 & 11.679 & 11.294 & 10.724 \\
& Freq. & 2,972 & 3,746 & 3,084 & 4,001 \\
\hline \multirow{4}{*}{ Male } & Mean & 11.373 & 10.937 & 10.218 & 9.172 \\
& S.D. & 14.728 & 14.378 & 13.703 & 13.394 \\
& Freq. & 1,395 & 1,763 & 1,437 & 1,870 \\
\hline \multirow{4}{*}{ Female } & Mean & 2.193 & 2.038 & 2.081 & 1.785 \\
& S.D. & 6.223 & 6.054 & 6.649 & 5.748 \\
& Freq. & 1,577 & 1,983 & 1,647 & 2,131 \\
\hline
\end{tabular}

(Panel B) Cigare tte consumption (S mokers)

\begin{tabular}{rlrrrr}
\hline & & \multicolumn{1}{c}{2005} & \multicolumn{1}{c}{2006} & \multicolumn{1}{c}{2007} & \multicolumn{1}{c}{2008} \\
\hline \multirow{4}{*}{ All } & Mean & 21.517 & 21.879 & 21.820 & 20.873 \\
& S.D. & 12.296 & 11.697 & 11.222 & 11.488 \\
& Freq. & 898 & 1,066 & 830 & 1,004 \\
\hline \multirow{4}{*}{ Male } & Mean & 24.483 & 24.253 & 23.760 & 23.368 \\
& S.D. & 12.077 & 11.635 & 10.712 & 11.193 \\
& Freq. & 648 & 795 & 618 & 734 \\
\hline \multirow{4}{*}{ Female } & Mean & 13.832 & 14.916 & 16.166 & 14.092 \\
& S.D. & 9.136 & 8.734 & 10.777 & 9.355 \\
& Freq. & 250 & 271 & 212 & 270 \\
\hline
\end{tabular}

(Panel C) Smoking rates

\begin{tabular}{llcccc}
\hline & & 2005 & 2006 & 2007 & 2008 \\
\hline \multirow{2}{*}{ All } & Mean & 0.264 & 0.258 & 0.245 & 0.224 \\
& S.D. & 0.441 & 0.437 & 0.430 & 0.417 \\
& Freq. & 2,972 & 3,746 & 3,084 & 4,001 \\
\hline \multirow{4}{*}{ Male } & Mean & 0.424 & 0.419 & 0.404 & 0.367 \\
& S.D. & 0.494 & 0.494 & 0.491 & 0.482 \\
& Freq. & 1,395 & 1,763 & 1,437 & 1,870 \\
\hline \multirow{2}{*}{ Female } & Mean & 0.122 & 0.114 & 0.106 & 0.099 \\
& S.D. & 0.327 & 0.318 & 0.308 & 0.299 \\
& Freq. & 1,577 & 1,983 & 1,647 & 2,131 \\
\hline
\end{tabular}

Note: The data are from the Japan Household Panel Survey on Consumer Preferences and Satisfaction from 2005 to 2008. Summary statistics of Panel A include nonsmokers in samples. Panel B shows the statistics only smokers. Panel C shows rates of regular smokers. 
Table 3: Question to elicit discount rates: An example (QUESTION 1 for DR D $_{1}$

Suppose you have two options to receive some money. You may choose Option "A", to receive 10,000 JPY in two days; or Option "B", to receive a different amount in nine days. Compare the amounts and timing in Option "A" with Option "B" and indicate which amount you would prefer to receive for each of all 8 choices.

\begin{tabular}{|c|c|c|c|c|}
\hline $\begin{array}{c}\text { Option A } \\
\text { (Receipt in 2 days) }\end{array}$ & $\begin{array}{c}\text { Option B } \\
\text { (Receipt in 9 days) }\end{array}$ & $\begin{array}{c}\text { Interest rate } \\
\text { (Annual) }\end{array}$ & \multicolumn{2}{|c|}{ Circle A or B. } \\
\hline \hline JPY 10,000 (USD 93.32) & JPY 9,981 (USD 93.14) & $-10 \%$ & A & B \\
\hline JPY 10,000 (USD 93.32) & JPY 10,000 (USD 93.32) & $0 \%$ & A & B \\
\hline JPY 10,000 (USD 93.32) & JPY 10,019 (USD 93.50) & $10 \%$ & A & B \\
\hline JPY 10,000 (USD 93.32) & JPY 10,038 (USD 93.67) & $20 \%$ & A & B \\
\hline JPY 10,000 (USD 93.32) & JPY 10,096 (USD 94.21) & $50 \%$ & A & B \\
\hline JPY 10,000 (USD 93.32) & JPY 10,191 (USD 95.10) & $100 \%$ & A & B \\
\hline JPY 10,000 (USD 93.32) & JPY 10,383 (USD 96.89) & $200 \%$ & A & B \\
\hline JPY 10,000 (USD 93.32) & JPY 10,574 (USD 98.67) & $300 \%$ & A & B \\
\hline
\end{tabular}

Note: This is a question in the Japan Household Panel Survey on Consumer Preferences and Satisfaction from 2005 to 2008. The US dollar amounts are computed by using the average JPY/ USD exchange rate, 107.16, in February, 2008. 


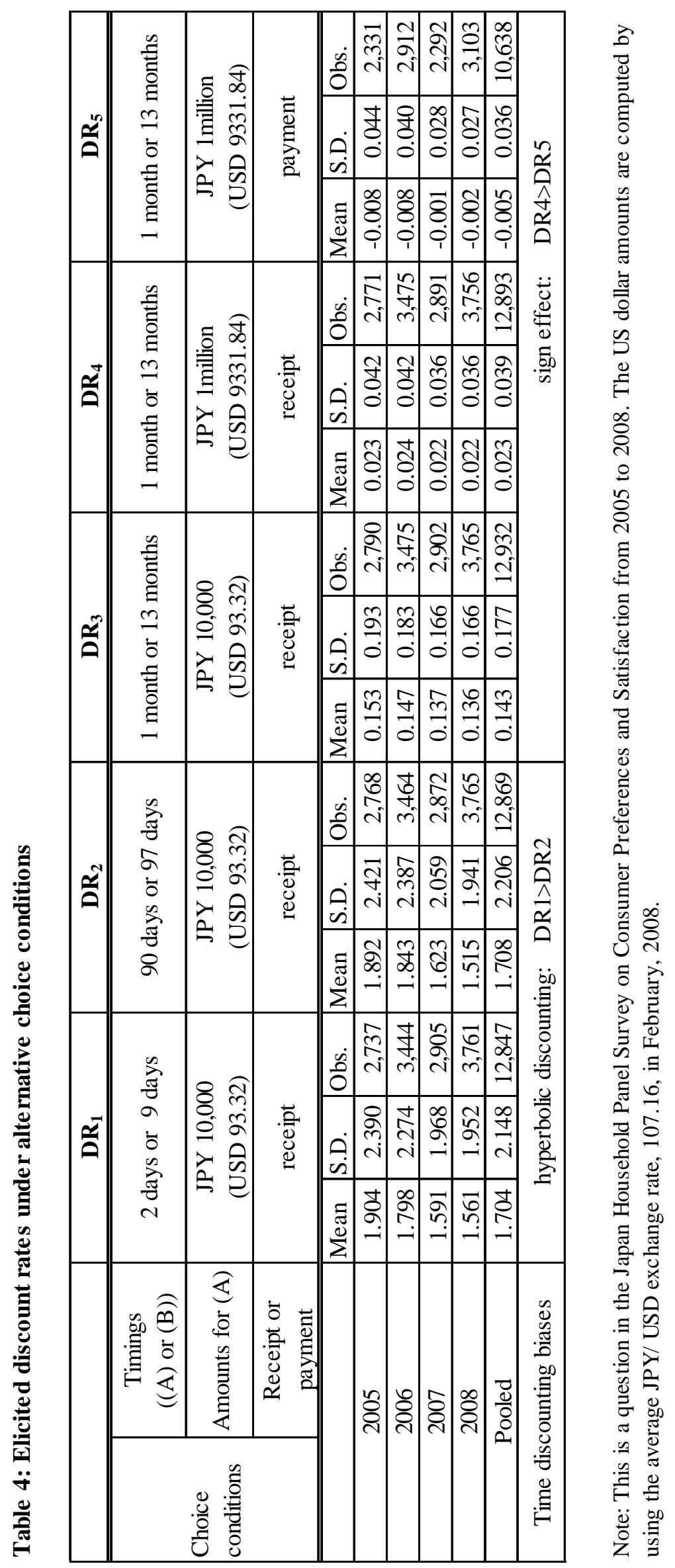


Table 5: Correlation coefficients of time discounting variables with SMOKING

\begin{tabular}{|c|c|c|c|}
\hline & \multicolumn{3}{|c|}{ SMOKING } \\
\hline & All & Male & Female \\
\hline DISCRATE & $\begin{array}{l}0.116 \text { *** } \\
(0.000)\end{array}$ & $\begin{array}{l}0.075 \text { *** } \\
(0.000)\end{array}$ & $\begin{array}{l}0.045 \text { *** } \\
(0.001)\end{array}$ \\
\hline HYPERBOL & $\begin{array}{l}-0.048 \text { *** } \\
(0.000)\end{array}$ & $\begin{array}{l}-0.039 * * * \\
(0.003)\end{array}$ & $\begin{array}{l}-0.015 \\
(0.219)\end{array}$ \\
\hline SIGN & $\begin{array}{l}-0.024 \text { ** } \\
(0.014)\end{array}$ & $\begin{array}{l}-0.035 \quad * * \\
(0.015)\end{array}$ & $\begin{array}{l}-0.024 * \\
(0.078)\end{array}$ \\
\hline PROCR & $\begin{array}{l}0.124 \text { *** } \\
(0.000)\end{array}$ & $\begin{array}{l}0.084 \text { *** } \\
(0.000)\end{array}$ & $\begin{array}{l}0.059 \text { *** } \\
(0.000)\end{array}$ \\
\hline NAÏVE & $\begin{array}{l}0.063 \text { *** } \\
(0.000)\end{array}$ & $\begin{array}{l}0.063 \text { *** } \\
(0.000)\end{array}$ & $\begin{array}{l}0.057 \text { *** } \\
(0.000)\end{array}$ \\
\hline
\end{tabular}

Note: This table shows the correlation coefficients of cigarette consumption with time discounting variables. Samples include nonsmokers.

$\mathrm{P}$-values are in parentheses.

$*, * *, * * *$ denote statistical significance at the $10 \%, 5 \%$, and $10 \%$ levels, respectively. 
Table 6: Definition, summary statistics, and hypothesized signs of variables

\begin{tabular}{|c|c|c|c|c|c|c|}
\hline \multicolumn{2}{|c|}{ Variables } & Definition & Mean & S.D. & Obs. & Hypothesis \\
\hline $\begin{array}{c}\text { Cigarette } \\
\text { consumption }\end{array}$ & SMOKING & The amount of cigarette consumptioon per day. & 5.920 & 11.398 & 13,803 & \\
\hline $\begin{array}{c}\text { Taxation } \\
\text { level }\end{array}$ & TAX & $\begin{array}{l}\text { Taxation level per cigarette. } 7.892 \text { yen from } 2005 \text { to } 2006 \text { and } 8.744 \text { yen } \\
\text { from } 2007 \text { to } 2008 \text {. }\end{array}$ & 8.330 & 0.426 & 13,880 & - \\
\hline \multirow{5}{*}{$\begin{array}{l}\text { Time } \\
\text { Preferences } \\
\text { factors }\end{array}$} & DISCRATE & $\begin{array}{l}\text { Simple mean, defined by equation }(1) \text {, of the standardized values of the } \\
\text { elicited discount rates } \operatorname{DR}_{i}(i=1, \ldots, 5) \text { as a measure of the degree of } \\
\text { impatience. }\end{array}$ & 0.042 & 0.718 & 10,125 & + \\
\hline & HYPERBOL & $\begin{array}{l}\text { A binary indicator for hyperbolic discounting which equals } 1 \text { if } \mathrm{DR}_{1}>\mathrm{DR}_{2} \text {, } \\
\text { and } 0 \text { otherwise. }\end{array}$ & 0.673 & 0.469 & 12,639 & + \\
\hline & PROCR & $\begin{array}{l}\text { Time averaged response to the question 'When did you do homework for the } \\
\text { vacation in your childhood?' on a 5-poit scale, from } 1 \text { (Homework was } \\
\text { finished at 'the beginning of the vacation') to } 5 \text { (it was not done until 'the } \\
\text { very end of the vacation'), which is a proxy measure of the degree of } \\
\text { procrastination. }\end{array}$ & 3.262 & 1.184 & 13,827 & + \\
\hline & NAÏVE & $\begin{array}{l}\text { Time averaged difference between respondents' plan and execution to do } \\
\text { homew ork in summer vacation in their high school day. }\end{array}$ & 1.117 & 1.206 & 11,638 & + \\
\hline & SIGN & $\begin{array}{l}\text { A binary indicator for the sign effect which equals } 1 \text { if } \mathrm{DR}_{4}>\mathrm{DR}_{5} \text {, and } 0 \\
\text { otherwise. }\end{array}$ & 0.903 & 0.296 & 10,450 & - \\
\hline \multirow{6}{*}{$\begin{array}{l}\text { Control } \\
\text { variables }\end{array}$} & RISKAV & $\begin{array}{l}\text { A variable which measures the degree of risk aversion, constructed by } \\
\text { subtracting from } 100 \text { the respondents' responses to the question: "When you } \\
\text { go out, how high probability of rainfall makes you bring an umbrella with } \\
\text { you?" }\end{array}$ & 50.160 & 20.203 & 13,654 & - \\
\hline & MALE & $\begin{array}{l}\text { A binary indicator for males which equals } 1 \text { for male respondents and } 0 \\
\text { otherwise. }\end{array}$ & 0.469 & 0.499 & 13,880 & + \\
\hline & UNIV & $\begin{array}{l}\text { A binary indicator for university graduates which equals } 1 \text { for university } \\
\text { graduates and } 0 \text { otherwise. }\end{array}$ & 0.218 & 0.413 & 13,454 & - \\
\hline & INCOME & Per capita household income in ten thousand yen. & 223.615 & 174.910 & 11,608 & - \\
\hline & AGE & Ages of respondents. & 49.686 & 13.058 & 13,880 & + \\
\hline & CHILD & $\begin{array}{l}\text { A binary indic ator for parent of children which equals } 1 \text { for respondents with } \\
\text { childlen and } 0 \text { otherwise. }\end{array}$ & 0.811 & 0.391 & 13,639 & - \\
\hline
\end{tabular}

Note: "Hypothesis" shows the theoritically predicted signs of associations with smoking. 
Table 7: Correlations between control variables and SMOKING

\begin{tabular}{|c|c|c|c|c|c|}
\hline & & & SMOKING & & \\
\hline & All & & Male & Female & \\
\hline MALE & $\begin{array}{r}0.366 \\
(0.000)\end{array}$ & $* * *$ & NA & A & \\
\hline UNIV & $\begin{array}{l}-0.017 \\
(0.050)\end{array}$ & & $\begin{array}{l}-0.130 \quad * * * \\
(0.000)\end{array}$ & $\begin{array}{l}-0.067 \\
(0.000)\end{array}$ & \\
\hline RISKAV & $\begin{array}{l}-0.099 \\
(0.000)\end{array}$ & & $\begin{array}{l}-0.111 \text { *** } \\
(0.000)\end{array}$ & $\begin{array}{l}-0.062 \\
(0.000)\end{array}$ & \\
\hline INCOME & $\begin{array}{r}0.003 \\
(0.719)\end{array}$ & & $\begin{array}{c}0.001 \\
(0.927)\end{array}$ & $\begin{array}{l}-0.042 \\
(0.001)\end{array}$ & \\
\hline AGE & $\begin{array}{l}-0.034 \\
(0.000)\end{array}$ & & $\begin{array}{l}-0.056 \text { *** } \\
(0.000)\end{array}$ & $\begin{array}{l}-0.107 \\
(0.000)\end{array}$ & \\
\hline CHILD & $\begin{array}{l}-0.032 \\
(0.000)\end{array}$ & & $\begin{array}{c}0.003 \\
(0.820)\end{array}$ & $\begin{array}{l}-0.039 \\
(0.001)\end{array}$ & \\
\hline
\end{tabular}

Notes: This table shows the correlation coefficients of cigarette consumption with control variables. Samples include nonsmokers.

$\mathrm{P}$-values are in parentheses.

$*, * *, * * *$ denote statistical significance at the $10 \%, 5 \%$, and $10 \%$ levels, respectively. 


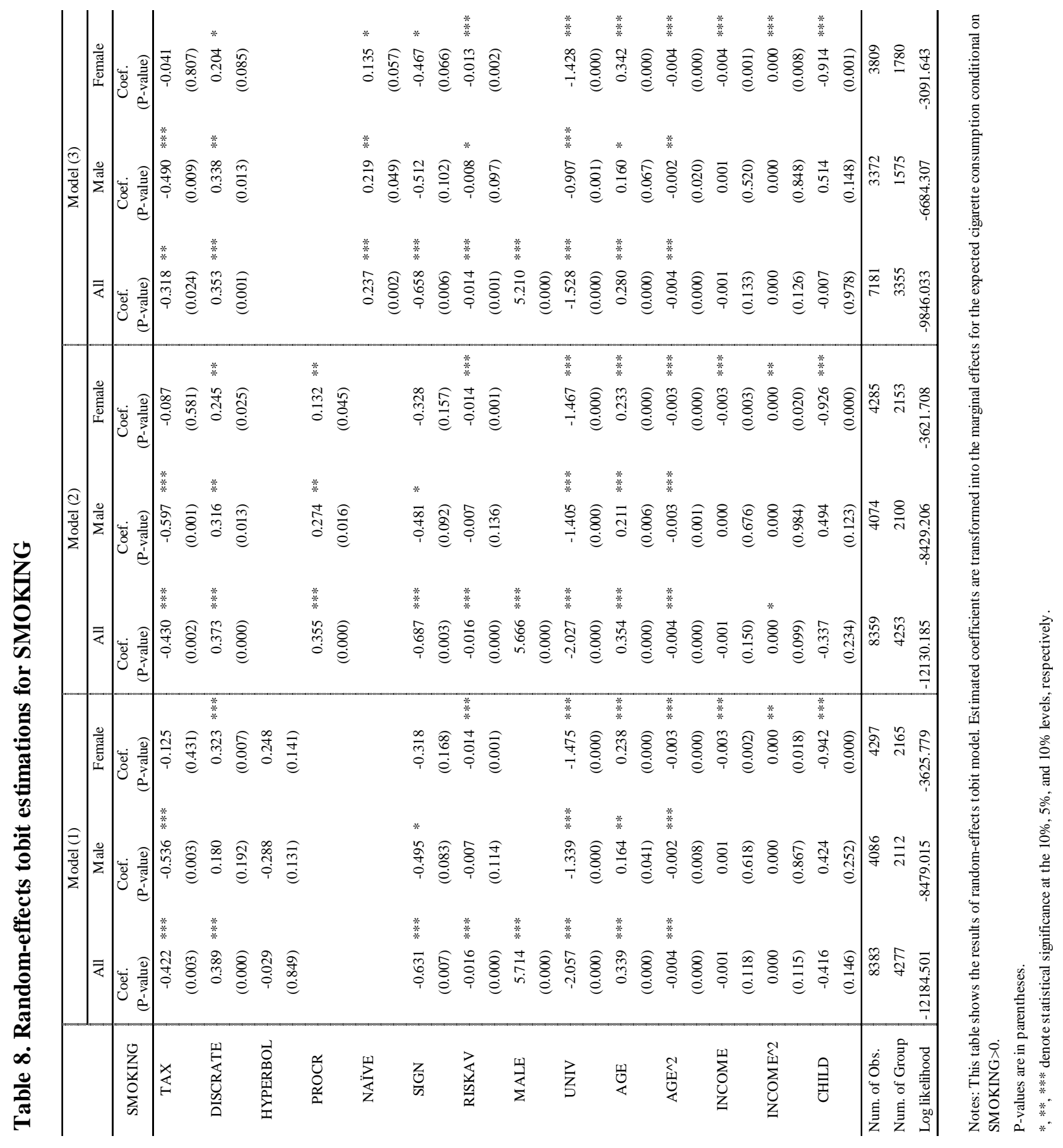


Table 9: Comparing the marginal effects of tax hikes for each agent HYPERBOL and PROCR)

(Panel A) HYPERBOL

\begin{tabular}{l|c|c}
\hline & $\begin{array}{c}\text { Hyperbolic } \\
\text { (HYPERBOL=1) }\end{array}$ & $\begin{array}{c}\text { Exponential } \\
\text { (HYPERBOL=0) }\end{array}$ \\
\hline All & $-0.412 \quad * *$ & -0.226 \\
& $(0.023)$ & $(0.415)$ \\
Difference & -0.186 & \\
\hline Male & $-0.642 * * *$ & -0.199 \\
& $(0.007)$ & $(0.497)$ \\
Difference & 0.442 & \\
\hline Female & -0.154 & -0.181 \\
& $(0.452)$ & $(0.634)$ \\
Difference & 0.027 & \\
\hline
\end{tabular}

(Panel B) PROCR

\begin{tabular}{l|c|c|c}
\hline & $\begin{array}{c}\text { Strong } \\
\text { procrastination } \\
(\mathrm{PROCR}=5)\end{array}$ & $\begin{array}{c}\text { Procrastination } \\
(5>\mathrm{PROCR} \geq 3)\end{array}$ & $\begin{array}{c}\text { Weak/ No } \\
\text { procrastination } \\
(\mathrm{PROCR}<3)\end{array}$ \\
\hline All & $-0.975 * *$ & $-0.393^{* *}$ & -0.451 \\
$(0.047)$ & $(0.043)$ & $(0.174)$ \\
\hline Difference & -0.524 & & $-0.968 * * *$ \\
& $-1.120 *$ & -0.336 & $(0.002)$ \\
Difference & $(0.061)$ & $(0.139)$ & \\
\hline Female & -0.153 & & 0.159 \\
& -0.643 & -0.487 & $(0.525)$ \\
Difference & $(0.403)$ & $(0.402)$ & \\
\hline
\end{tabular}

Notes: This tables show the coefficients of marginal effects of TAX by estimating randomeffects tobit models. Samples are sorted by using NAIVE. SMOKING is used as an explained variable and DRSTD, SIGN, RISKAV, MALE, UNIV, AGE, AGE^2, INCOME,

INCOME^2, and CHILD are used as explanatory variables.

$\mathrm{P}$-values are in parentheses.

$*, * *, * *$ denote statistical significance at the $10 \%, 5 \%$, and $10 \%$ levels, respectively.

"Difference" shows the differences between marginal effects of Hyperbolic and Exponential in Panel A, and the differences between marginal effeccts of Strong procrastination and Weak/ No Procrastination in Panel B. 
Table 10: Comparing the marginal effects of tax hikes for each agent NAÏVE)

\begin{tabular}{l|c|c|c}
\hline & $\begin{array}{c}\text { Strong naïve } \\
\text { (NAÏVE=4) }\end{array}$ & $\begin{array}{c}\text { Naïve } \\
(4>\text { NAÏVE } \geqq 1)\end{array}$ & $\begin{array}{c}\text { Sophisticate } \\
(\mathrm{NAÏVE}<1)\end{array}$ \\
\hline All & $-2.106 * *$ & $-0.344^{* * *}$ & -0.140 \\
Difference & -1.966 & $(0.006)$ & $(0.551)$ \\
\hline Male & -1.512 & $-1.296 * *$ & -0.407 \\
& $(0.180)$ & $(0.030)$ & $(0.202)$ \\
Difference & -1.105 & & 0.193 \\
\hline Female & $-3.907 * * *$ & -2.678 & $(0.507)$ \\
& $(0.001)$ & $(0.623)$ & \\
Difference & -4.100 & & \\
\hline
\end{tabular}

Notes: This table shows the coefficients of marginal effects of TAX by estimating randomeffects tobit models. Samples are sorted by using NAIVE. SMOKING is used as an explained variable and DRSTD, SIGN, RISKAV, M ALE, UNIV, AGE, AGE^2, INCOME,

$\mathrm{INCOME}^{\wedge} 2$, and CHILD are used as explanatory variables.

$\mathrm{P}$-values are in parentheses.

$*, * *, * * *$ denote statistical significance at the $10 \%, 5 \%$, and $10 \%$ levels, respectively.

"Difference" shows the differences between marginal effects of Strong naive and Sophisticate. 
Table 11: Tax hikes, smoking moderation, and increasing rates of tax revenue

Model (1): The marginal effect of TAX= -0.416

\begin{tabular}{l|c|ccc} 
& before tax hikes & \multicolumn{3}{c}{ after tax hikes } \\
\hline \multirow{2}{*}{ Cigarette price per pack } & JPY 300 & JPY 500 & JPY 700 & JPY 1000 \\
& (USD 2.80) & (USD 4.67) & (USD 6.53) & (USD 9.33) \\
\hline \multirow{2}{*}{$\Delta$ TAX per cigarette } & JPY 0 & JPY 10 & JPY 20 & JPY 35 \\
(USD 0) & (USD 0.09) & (USD 0.19) & (USD 0.33) \\
\hline Averaged cigarette consumption & 20.873 & 18.880 & 14.725 & 13.956 \\
Smoking rates & $25.1 \%$ & $22.4 \%$ & $22.4 \%$ & $15.6 \%$ \\
Smoking cessation rates for smokers & $0.0 \%$ & $10.7 \%$ & $10.7 \%$ & $37.8 \%$ \\
\hline Increasing rates of revenues & $0.0 \%$ & $73.2 \%$ & $107.2 \%$ & $107.9 \%$
\end{tabular}

Notes: This tabel shows the predicted smoking status and increasing rates of government's revenues responding to tax hikes by JPY 10, 20, and 35 (around USD 0.09, 0.19, and 0.33) per cigarette. The estimated coefficient of TAX in model (1) for full samples is used for the predictions. The marginal effect is measured around mean values of smokers in 2008. The row of "Cigarette price per pack" shows the hypothetical prices per 20-cigarette pack after tax hikes calculated by $(20 * \triangle \mathrm{TAX}$ per cigarette). The row of " $\triangle \mathrm{TAX}$ per cigarette" shows the increased rates of tax per cigarette. The rows of "Averaged cigarette consumption", "Smoking rates", and "Smoking cessation rates for smokers" show the resulting status of cigarette consumption after tax hikes. The row of "Increasing rates of revenues" shows the net increasing rates of government's revenues by hiking cigarette tax. 
Figure 1: Transition graphs of smoking behavior

(Panel A) Cigare tte consumption

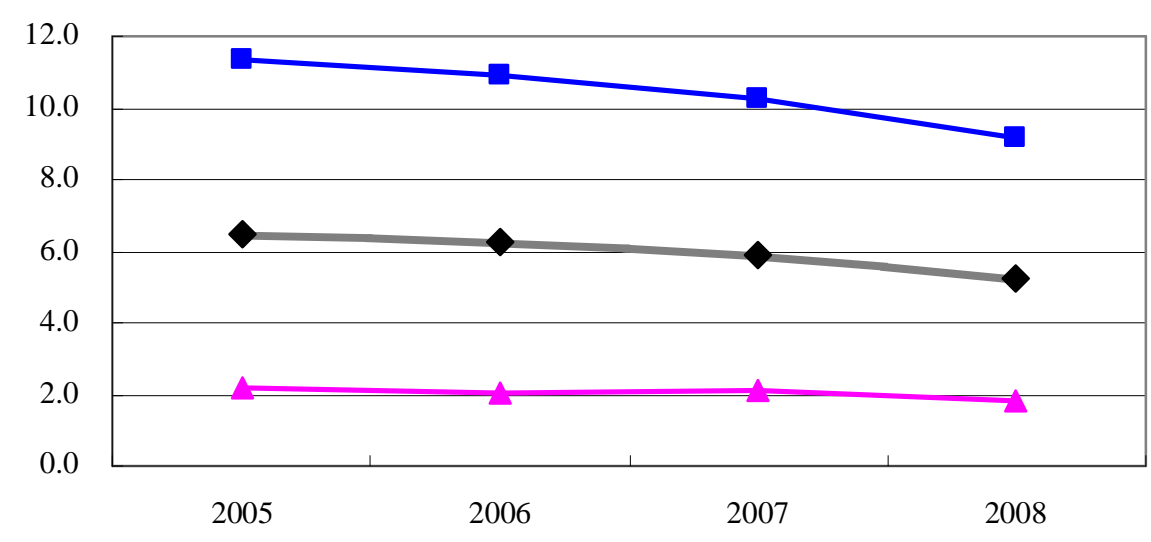

(Panel B) Cigare tte consumption (Smokers)

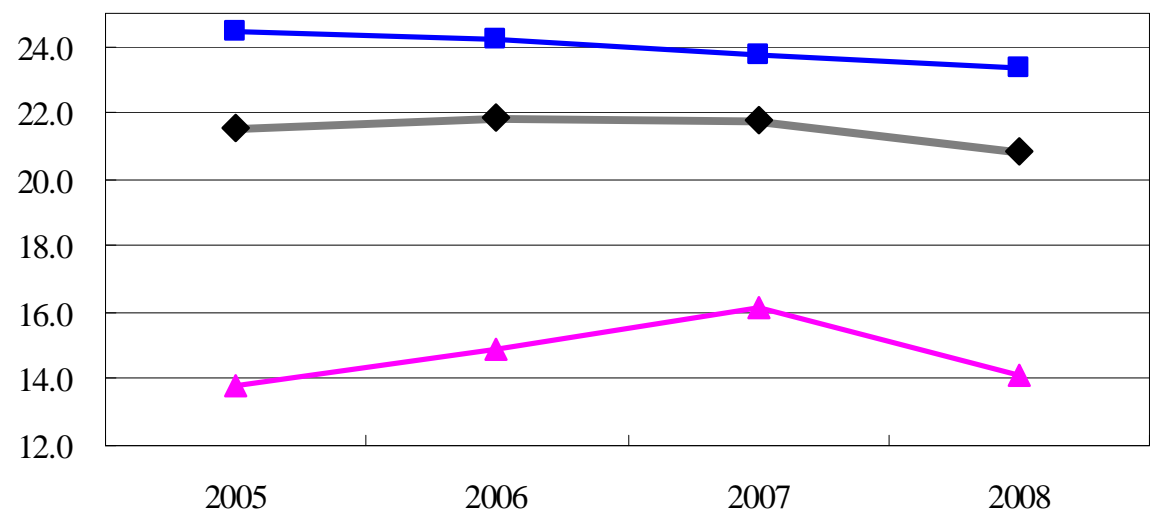

(Panel C) Smoking rates

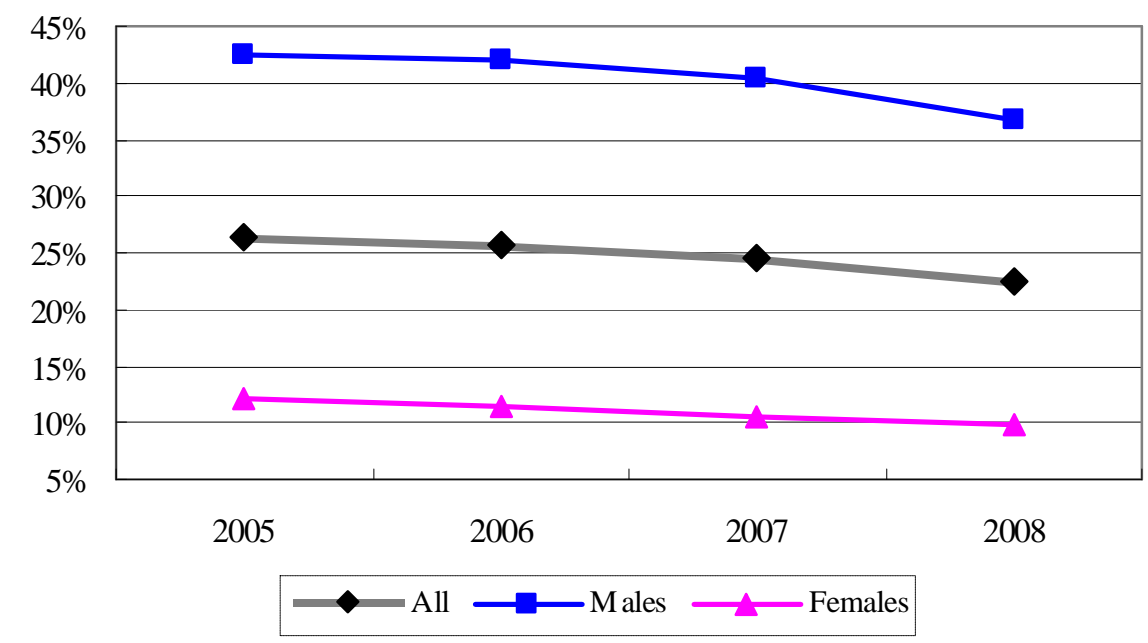

Note: The graphs show trends of smoking behavior. Panel A shows averaged cigarette consumption including nonsmokers in samples. Panel B shows ageraged cigarette consumption among smokers. Panel $\mathrm{C}$ shows rates of regular smokers. 
Figure 2: Distributions of PROCR and NAÏVE

(Panel A) PROCR

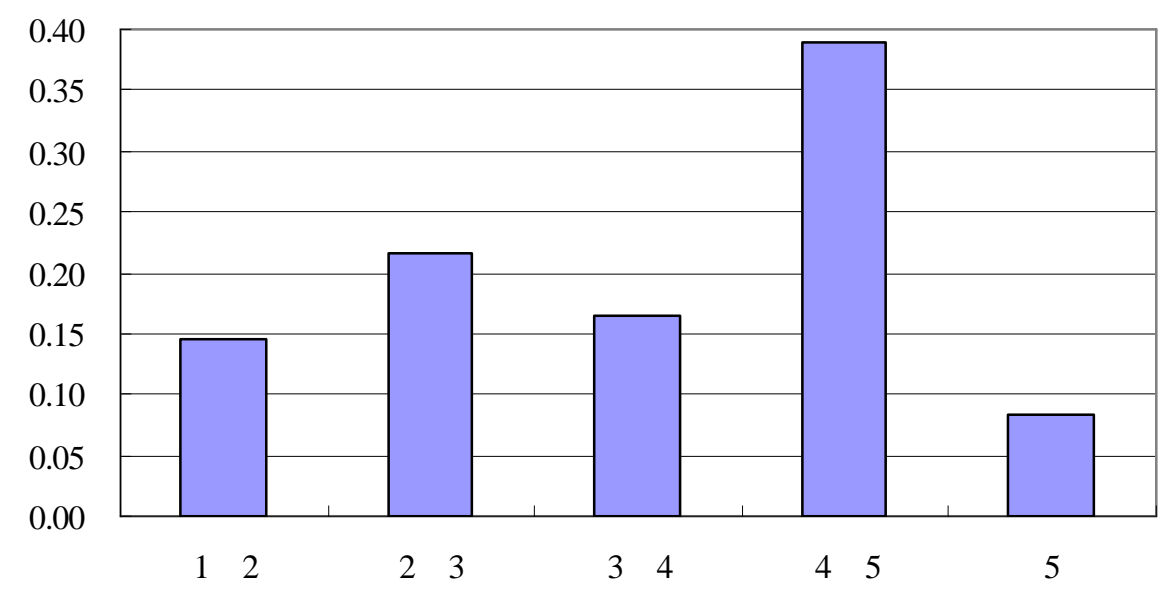

(Panel B) NAÏVE

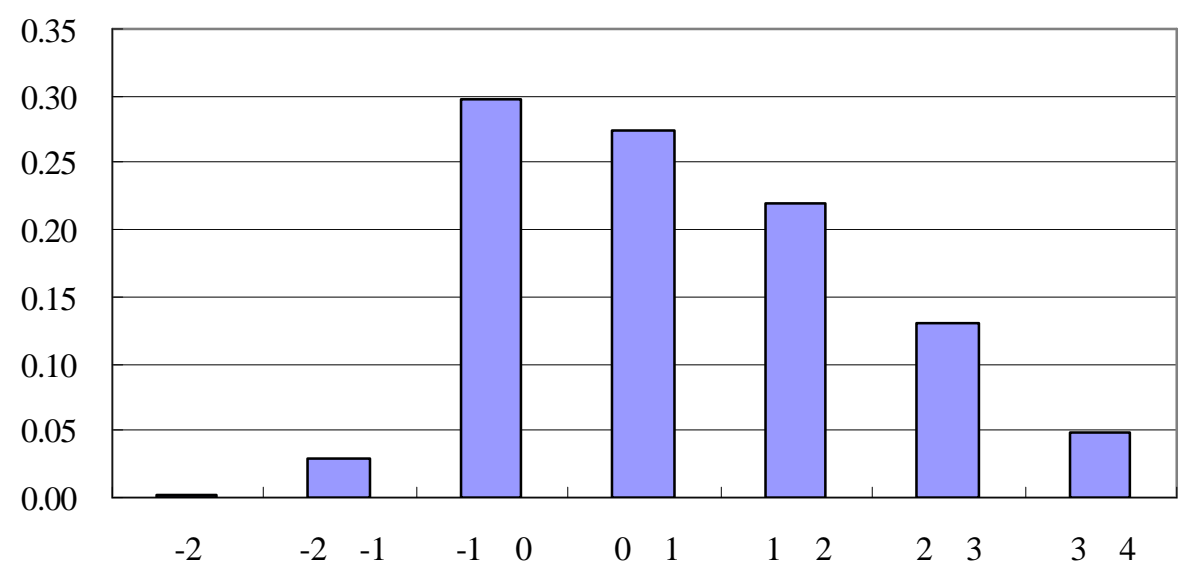


Figure 3: Age trends of ave raged cigarette consumption of smokers

\section{(Panel A) All}

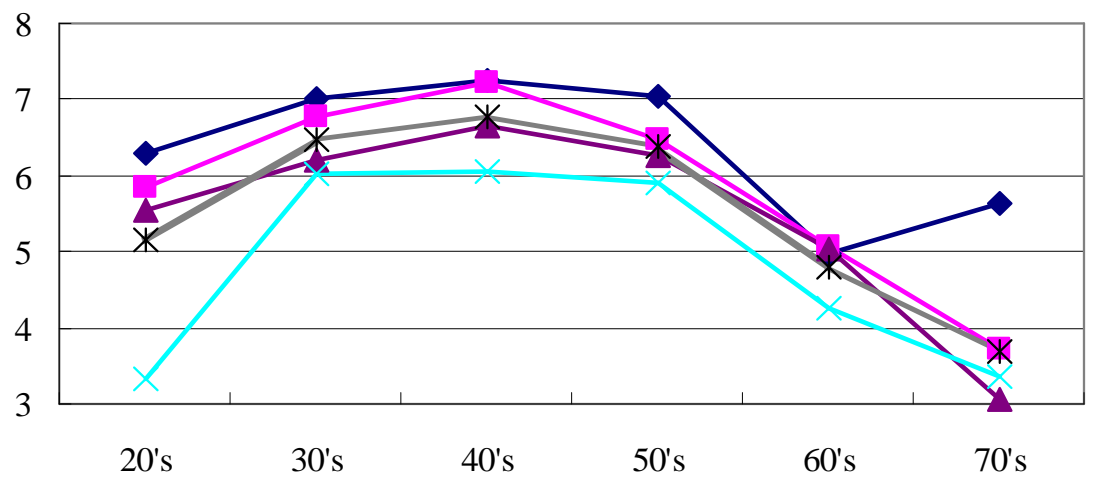

(Panel B) Males

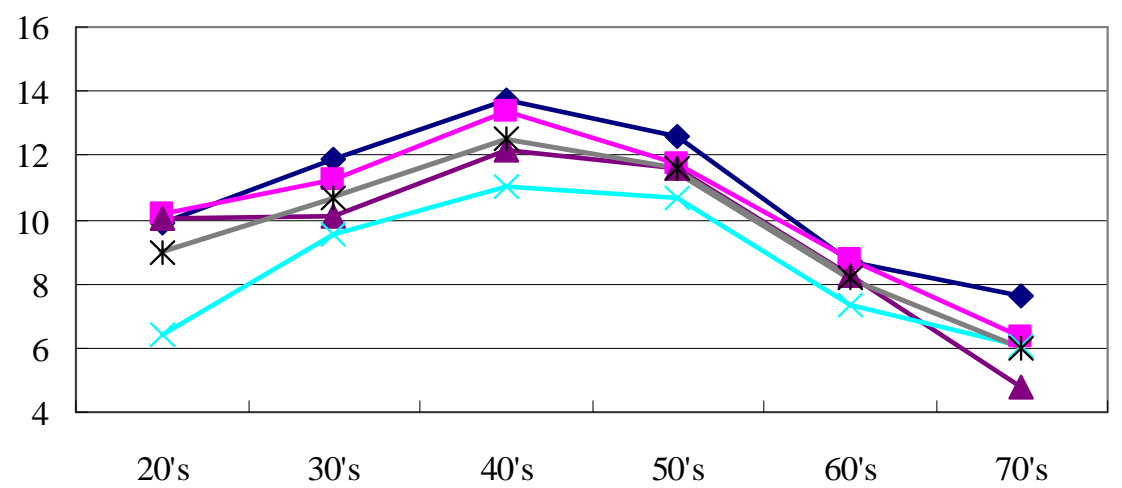

(Panel C) Females

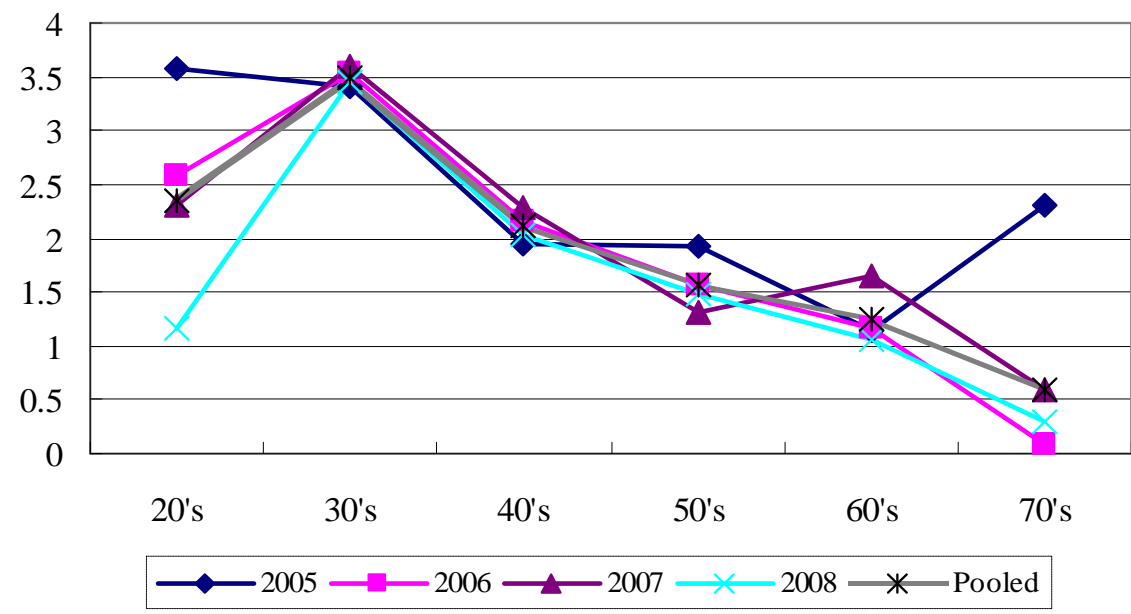

Notes: the graphs show the age trends of averaged cigarette consumption including nonsmokers. The horizonal axes indicate the averaged number of cigarette consumption. The vertical axes indicate age brackets. 
Figure 4: Tax hikes and the increasing rates of tax revenue

The marginal effect of TAX= $\mathbf{- 0 . 4 1 6}(\operatorname{model}(1))$

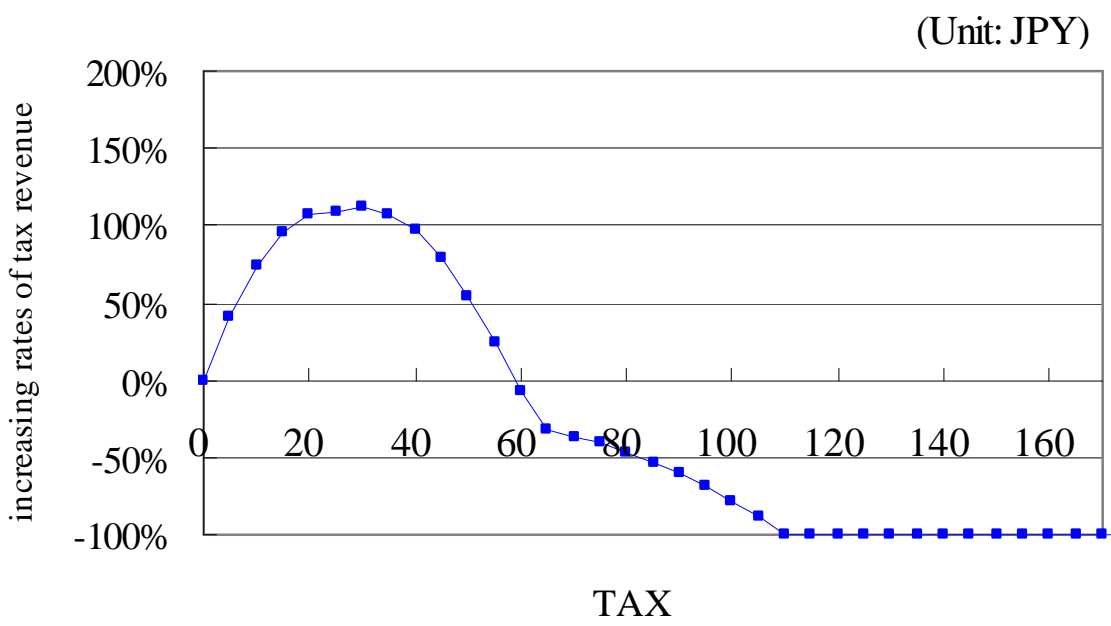

Notes: This figure shows the predicted increasing rates of government's revenues responding to tax hikes. The horizonal axis indicates increased rates of tax per cigarette. The vertical axis indicates net increasing rates of government's revenues by hiking cigarette tax in JPY terms. The estimated coefficient of TAX in model (1) for full samples is used for the predictions. The marginal effect is measured around mean values of smokers in 2008 . 


\section{All samples}

2005

\begin{tabular}{lcrrrr}
\hline \multicolumn{1}{c}{ Variable } & Obs & \multicolumn{1}{c}{ Mean } & Std. Dev. & \multicolumn{1}{l}{ Min } & \multicolumn{1}{l}{ Max } \\
\hline DR1 & 2737 & 1.904 & 2.390 & -0.369 & 5.724 \\
DR2 & 2768 & 1.892 & 2.421 & -0.373 & 5.742 \\
DR3 & 2790 & 0.153 & 0.193 & -0.121 & 0.512 \\
DR4 & 2771 & 0.023 & 0.042 & -0.065 & 0.118 \\
DR5 & 2331 & -0.008 & 0.044 & -0.073 & 0.117 \\
DISCRATE & 2202 & 0.042 & 0.688 & -1.376 & 2.033 \\
HYPERBOL & 2694 & 0.621 & 0.485 & 0 & 1 \\
SIGN & 2289 & 0.885 & 0.319 & 0 & 1 \\
PROCR & 2963 & 3.263 & 1.195 & 1 & 5 \\
NAIVE & 1951 & 1.087 & 1.196 & -2 & 4 \\
\hline
\end{tabular}

2006

\begin{tabular}{lrrrrr}
\hline \multicolumn{1}{c}{ Variable } & Obs & \multicolumn{1}{c}{ Mean } & Std. Dev. & \multicolumn{1}{l}{ Min } & \multicolumn{1}{c}{ Max } \\
\hline DR1 & 3444 & 1.798 & 2.274 & -0.363 & 5.537 \\
DR2 & 3464 & 1.843 & 2.387 & -0.372 & 5.675 \\
DR3 & 3475 & 0.147 & 0.183 & -0.117 & 0.503 \\
DR4 & 3475 & 0.024 & 0.042 & -0.065 & 0.118 \\
DR5 & 2912 & -0.008 & 0.040 & -0.070 & 0.115 \\
DISCRATE & 2784 & 0.033 & 0.693 & -1.396 & 2.099 \\
HYPERBOL & 3412 & 0.585 & 0.493 & 0 & 1 \\
SIGN & 2862 & 0.902 & 0.297 & 0 & 1 \\
PROCR & 3747 & 3.277 & 1.171 & 1 & 5 \\
NAIVE & 2962 & 1.120 & 1.201 & -2 & 4 \\
\hline
\end{tabular}

2007

\begin{tabular}{lcrrrr}
\hline \multicolumn{1}{c}{ Variable } & \multicolumn{1}{c}{ Obs } & \multicolumn{1}{c}{ Mean } & Std. Dev. & \multicolumn{1}{l}{ Min } & M ax \\
\hline DR1 & 2905 & 1.591 & 1.968 & -0.339 & 5.074 \\
DR2 & 2872 & 1.623 & 2.059 & -0.348 & 5.188 \\
DR3 & 2902 & 0.137 & 0.166 & -0.110 & 0.487 \\
DR4 & 2891 & 0.022 & 0.036 & -0.062 & 0.114 \\
DR5 & 2292 & -0.001 & 0.028 & -0.061 & 0.108 \\
DISCRATE & 2190 & 0.048 & 0.753 & -1.580 & 2.407 \\
HYPERBOL & 2844 & 0.587 & 0.492 & 0 & 1 \\
SIGN & 2249 & 0.914 & 0.280 & 0 & 1 \\
PROCR & 3112 & 3.260 & 1.162 & 1 & 5 \\
NAIVE & 2962 & 1.120 & 1.201 & -2 & 4 \\
\hline
\end{tabular}

2008

\begin{tabular}{lcrrrr}
\hline \multicolumn{1}{c}{ Variable } & Obs & \multicolumn{1}{c}{ Mean } & Std. Dev. & \multicolumn{1}{l}{ Min } & \multicolumn{1}{l}{ M ax } \\
\hline DR1 & 3761 & 1.561 & 1.952 & -0.339 & 5.041 \\
DR2 & 3765 & 1.515 & 1.941 & -0.341 & 5.017 \\
DR3 & 3765 & 0.136 & 0.166 & -0.110 & 0.487 \\
DR4 & 3756 & 0.022 & 0.036 & -0.062 & 0.114 \\
DR5 & 3103 & -0.002 & 0.027 & -0.061 & 0.108 \\
DISCRATE & 2949 & 0.045 & 0.737 & -1.576 & 2.450 \\
HYPERBOL & 3689 & 0.860 & 0.347 & 0 & 1 \\
SIGN & 3050 & 0.910 & 0.287 & 0 & 1 \\
PROCR & 4005 & 3.248 & 1.205 & 1 & 5 \\
NAIVE & 3763 & 1.129 & 1.219 & -2 & 4 \\
\hline
\end{tabular}

Pooled

\begin{tabular}{llrrrr}
\hline \multicolumn{1}{c}{ Variable } & Obs & \multicolumn{1}{c}{ Mean } & Std. Dev. & M in & M ax \\
\hline DR1 & 12847 & 1.704 & 2.148 & -0.369 & 5.724 \\
DR2 & 12869 & 1.708 & 2.206 & -0.373 & 5.742 \\
DR3 & 12932 & 0.143 & 0.177 & -0.121 & 0.512 \\
DR4 & 12893 & 0.023 & 0.039 & -0.065 & 0.118 \\
DR5 & 10638 & -0.005 & 0.036 & -0.073 & 0.117 \\
DISCRATE & 10125 & 0.042 & 0.718 & -1.580 & 2.450 \\
HYPERBOL & 12639 & 0.673 & 0.469 & 0 & 1 \\
SIGN & 10450 & 0.903 & 0.296 & 0 & 1 \\
PROCR & 13827 & 3.262 & 1.184 & 1 & 5 \\
NAIVE & 14156 & 1.111 & 1.202 & -2 & 4 \\
\hline
\end{tabular}

Male samples

\section{5}

\begin{tabular}{lrrrrr}
\hline \multicolumn{1}{c}{ Variable } & \multicolumn{1}{c}{ Obs } & \multicolumn{1}{c}{ Mean } & Std. Dev. & \multicolumn{1}{l}{ Min } & \multicolumn{1}{l}{ Max } \\
\hline DR 1 & 1296 & 2.088 & 2.442 & -0.369 & 5.724 \\
DR2 & 1307 & 2.075 & 2.484 & -0.373 & 5.742 \\
DR3 & 1320 & 0.172 & 0.198 & -0.121 & 0.512 \\
DR4 & 1312 & 0.028 & 0.043 & -0.065 & 0.118 \\
DR5 & 1116 & -0.006 & 0.045 & -0.073 & 0.117 \\
DISCRATE & 1051 & 0.132 & 0.707 & -1.376 & 2.033 \\
HYPERBOL & 1271 & 0.595 & 0.491 & 0 & 1 \\
SIGN & 1096 & 0.885 & 0.319 & 0 & 1 \\
PROCR & 1395 & 3.485 & 1.155 & 1 & 5 \\
NAIVE & 860 & 1.129 & 1.217 & -2 & 4 \\
\hline
\end{tabular}

2006

\begin{tabular}{lcrrrr}
\hline \multicolumn{1}{c}{ Variable } & \multicolumn{1}{c}{ Obs } & \multicolumn{1}{c}{ Mean } & Std. Dev. & \multicolumn{1}{l}{ Min } & \multicolumn{1}{l}{ Max } \\
\hline DR1 & 1631 & 2.060 & 2.361 & -0.363 & 5.537 \\
DR2 & 1639 & 2.111 & 2.489 & -0.372 & 5.675 \\
DR3 & 1655 & 0.170 & 0.191 & -0.117 & 0.503 \\
DR4 & 1656 & 0.031 & 0.044 & -0.065 & 0.118 \\
DR5 & 1386 & -0.005 & 0.042 & -0.070 & 0.115 \\
DISCRATE & 1322 & 0.158 & 0.730 & -1.396 & 2.099 \\
HYPERBOL & 1611 & 0.540 & 0.499 & 0 & 1 \\
SIGN & 1363 & 0.902 & 0.298 & 0 & 1 \\
PROCR & 1767 & 3.487 & 1.135 & 1 & 5 \\
NAIVE & 1348 & 1.165 & 1.204 & -2 & 4 \\
\hline
\end{tabular}

2007

\begin{tabular}{lcrrrr}
\hline \multicolumn{1}{c}{ Variable } & Obs & Mean & Std. Dev. & \multicolumn{1}{l}{ Min } & \multicolumn{1}{l}{ Max } \\
\hline DR 1 & 1350 & 1.851 & 2.059 & -0.339 & 5.074 \\
DR2 & 1331 & 1.847 & 2.136 & -0.348 & 5.188 \\
DR3 & 1350 & 0.162 & 0.176 & -0.110 & 0.487 \\
DR4 & 1345 & 0.029 & 0.038 & -0.062 & 0.114 \\
DR5 & 1071 & 0.002 & 0.031 & -0.061 & 0.108 \\
DISCRATE & 1010 & 0.196 & 0.795 & -1.580 & 2.407 \\
HYPERBOL & 1317 & 0.547 & 0.498 & 0 & 1 \\
SIGN & 1046 & 0.922 & 0.269 & 0 & 1 \\
PROCR & 1449 & 3.467 & 1.124 & 1 & 5 \\
NAIVE & 1348 & 1.165 & 1.204 & -2 & 4 \\
\hline
\end{tabular}

2008

\begin{tabular}{lcrrrr}
\hline \multicolumn{1}{c}{ Variable } & Obs & Mean & Std. Dev. & \multicolumn{1}{l}{ Min } & \multicolumn{1}{l}{ Max } \\
\hline DR1 & 1761 & 1.819 & 2.040 & -0.339 & 5.041 \\
DR2 & 1762 & 1.752 & 2.043 & -0.341 & 5.017 \\
DR3 & 1760 & 0.157 & 0.176 & -0.110 & 0.487 \\
DR4 & 1757 & 0.028 & 0.039 & -0.062 & 0.114 \\
DR5 & 1481 & 0.000 & 0.030 & -0.061 & 0.108 \\
DISCRATE & 1416 & 0.173 & 0.781 & -1.576 & 2.450 \\
HYPERBOL & 1729 & 0.855 & 0.352 & 0 & 1 \\
SIGN & 1456 & 0.913 & 0.282 & 0 & 1 \\
PROCR & 1872 & 3.450 & 1.171 & 1 & 5 \\
NAIVE & 1711 & 1.148 & 1.208 & -2 & 4 \\
\hline
\end{tabular}

Pooled

\begin{tabular}{lcrrrr}
\hline \multicolumn{1}{c}{ Variable } & Obs & \multicolumn{1}{c}{ Mean } & Std. Dev. & \multicolumn{1}{l}{ M in } & \multicolumn{1}{c}{ Max } \\
\hline DR1 & 6038 & 1.949 & 2.227 & -0.369 & 5.724 \\
DR2 & 6039 & 1.940 & 2.294 & -0.373 & 5.742 \\
DR3 & 6085 & 0.165 & 0.185 & -0.121 & 0.512 \\
DR4 & 6070 & 0.029 & 0.041 & -0.065 & 0.118 \\
DR5 & 5054 & -0.002 & 0.038 & -0.073 & 0.117 \\
DISCRATE & 4799 & 0.165 & 0.754 & -1.580 & 2.450 \\
HYPERBOL & 5928 & 0.645 & 0.478 & 0 & 1 \\
SIGN & 4961 & 0.905 & 0.293 & 0 & 1 \\
PROCR & 6483 & 3.471 & 1.147 & 1 & 5 \\
NAIVE & 6377 & 1.149 & 1.208 & -2 & 4 \\
\hline
\end{tabular}

Female samples

2005

\begin{tabular}{lrrrrr}
\hline \multicolumn{1}{c}{ Variable } & \multicolumn{1}{c}{ Obs } & \multicolumn{1}{c}{ Mean } & Std. Dev. & \multicolumn{1}{l}{ M in } & \multicolumn{1}{c}{ Max } \\
\hline DR1 & 1441 & 1.739 & 2.332 & -0.369 & 5.724 \\
DR2 & 1461 & 1.728 & 2.351 & -0.373 & 5.742 \\
DR3 & 1470 & 0.136 & 0.186 & -0.121 & 0.512 \\
DR4 & 1459 & 0.018 & 0.040 & -0.065 & 0.118 \\
DR5 & 1215 & -0.010 & 0.043 & -0.073 & 0.117 \\
DISCRATE & 1151 & -0.040 & 0.660 & -1.376 & 2.033 \\
HYPERBOL & 1423 & 0.644 & 0.479 & 0 & 1 \\
SIGN & 1193 & 0.884 & 0.320 & 0 & 1 \\
PROCR & 1568 & 3.066 & 1.196 & 1 & 5 \\
NAIVE & 1091 & 1.055 & 1.179 & -2 & 4 \\
\hline
\end{tabular}

2006

\begin{tabular}{lcrrrr}
\hline \multicolumn{1}{c}{ Variable } & \multicolumn{1}{c}{ Obs } & \multicolumn{1}{c}{ Mean } & Std. Dev. & \multicolumn{1}{l}{ Min } & \multicolumn{1}{l}{ Max } \\
\hline DR1 & 1813 & 1.563 & 2.168 & -0.363 & 5.537 \\
DR2 & 1825 & 1.602 & 2.265 & -0.372 & 5.675 \\
DR3 & 1820 & 0.125 & 0.173 & -0.117 & 0.503 \\
DR4 & 1819 & 0.017 & 0.039 & -0.065 & 0.118 \\
DR5 & 1526 & -0.010 & 0.038 & -0.070 & 0.115 \\
DISCRATE & 1462 & -0.079 & 0.637 & -1.396 & 2.099 \\
HYPERBOL & 1801 & 0.625 & 0.484 & 0 & 1 \\
SIGN & 1499 & 0.903 & 0.297 & 0 & 1 \\
PROCR & 1980 & 3.090 & 1.171 & 1 & 5 \\
NAIVE & 1614 & 1.083 & 1.198 & -2 & 4 \\
\hline
\end{tabular}

2007

\begin{tabular}{lrrrrr}
\hline \multicolumn{1}{c}{ Variable } & \multicolumn{1}{l}{ Obs } & \multicolumn{1}{l}{ Mean } & Std. Dev. & \multicolumn{1}{l}{ Min } & \multicolumn{1}{l}{ Max } \\
\hline DR1 & 1555 & 1.365 & 1.857 & -0.339 & 5.074 \\
DR2 & 1541 & 1.430 & 1.971 & -0.348 & 5.188 \\
DR3 & 1552 & 0.116 & 0.155 & -0.110 & 0.487 \\
DR4 & 1546 & 0.016 & 0.032 & -0.062 & 0.114 \\
DR5 & 1221 & -0.004 & 0.025 & -0.061 & 0.108 \\
DISCRATE & 1180 & -0.079 & 0.691 & -1.580 & 2.407 \\
HYPERBOL & 1527 & 0.622 & 0.485 & 0 & 1 \\
SIGN & 1203 & 0.908 & 0.290 & 0 & 1 \\
PROCR & 1663 & 3.079 & 1.165 & 1 & 5 \\
NAIVE & 1614 & 1.083 & 1.198 & -2 & 4 \\
\hline
\end{tabular}

2008

\begin{tabular}{lrrrrr}
\hline \multicolumn{1}{c}{ Variable } & Obs & \multicolumn{1}{c}{ Mean } & Std. Dev. & \multicolumn{1}{l}{ M in } & \multicolumn{1}{c}{ M ax } \\
\hline DR1 & 2000 & 1.334 & 1.842 & -0.339 & 5.041 \\
DR2 & 2003 & 1.307 & 1.822 & -0.341 & 5.017 \\
DR3 & 2005 & 0.117 & 0.155 & -0.110 & 0.487 \\
DR4 & 1999 & 0.018 & 0.033 & -0.062 & 0.114 \\
DR5 & 1622 & -0.005 & 0.024 & -0.061 & 0.108 \\
DISCRATE & 1533 & -0.074 & 0.674 & -1.576 & 2.450 \\
HYYERBOL & 1960 & 0.864 & 0.343 & 0 & 1 \\
SIGN & 1594 & 0.907 & 0.291 & 0 & 1 \\
PROCR & 2133 & 3.072 & 1.208 & 1 & 5 \\
NAIVE & 2052 & 1.112 & 1.228 & -2 & 4 \\
\hline
\end{tabular}

Pooled

\begin{tabular}{lcrrrr}
\hline \multicolumn{1}{c}{ Variable } & Obs & Mean & Std. Dev. & \multicolumn{1}{l}{ Min } & \multicolumn{1}{l}{ Max } \\
\hline DR1 & 6809 & 1.488 & 2.052 & -0.369 & 5.724 \\
DR2 & 6830 & 1.503 & 2.104 & -0.373 & 5.742 \\
DR3 & 6847 & 0.123 & 0.167 & -0.121 & 0.512 \\
DR4 & 6823 & 0.017 & 0.036 & -0.065 & 0.118 \\
DR5 & 5584 & -0.007 & 0.033 & -0.073 & 0.117 \\
DISCRATE & 5326 & -0.069 & 0.665 & -1.580 & 2.450 \\
HYPERBOL & 6711 & 0.698 & 0.459 & 0 & 1 \\
SIGN & 5489 & 0.901 & 0.299 & 0 & 1 \\
PROCR & 7344 & 3.077 & 1.186 & 1 & 5 \\
NAIVE & 7779 & 1.080 & 1.197 & -2 & 4 \\
\hline
\end{tabular}


Appendix B: Correlation coefficients of time discounting variables with SMOKING

2005

\begin{tabular}{lccc}
\hline & \multicolumn{3}{c}{ SMOKING } \\
\cline { 2 - 4 } & All & Male & Female \\
\hline DISCRATE & $0.094^{* * *}$ & $0.053 *$ & $0.056 *$ \\
& $(0.000)$ & $(0.087)$ & $(0.057)$ \\
\hline HYPERBOL & $-0.044^{* *}$ & -0.020 & $-0.047 *$ \\
& $(0.024)$ & $(0.474)$ & $(0.078)$ \\
\hline SIGN & $-0.036 *$ & -0.043 & -0.040 \\
& $(0.090)$ & $(0.156)$ & $(0.171)$ \\
\hline PROCR & $0.140^{* * *}$ & $0.080^{* * *}$ & 0.100 \\
& $(0.000)$ & $(0.003)$ & $(0.000)$ \\
\hline NAIVE & $0.087 * * *$ & $0.080 * *$ & 0.101 \\
& $(0.000)$ & $(0.019)$ & $(0.001)$ \\
\hline
\end{tabular}

2007

\begin{tabular}{lccc}
\hline & \multicolumn{3}{c}{ SMOKING } \\
\cline { 2 - 4 } & All & Male & Female \\
\hline DISCRATE & $0.140^{* * *}$ & $0.100^{* * *}$ & 0.056 \\
& $(0.000)$ & $(0.002)$ & $(0.056)$ \\
\hline HYPERBOL & $-0.074^{* * *}$ & $-0.065^{* *}$ & -0.028 \\
& $(0.000)$ & $(0.018)$ & $(0.282)$ \\
\hline SIGN & $-0.040^{*}$ & $-0.070^{* *}$ & -0.035 \\
& $(0.062)$ & $(0.025)$ & $(0.233)$ \\
\hline PROCR & $0.132^{* * *}$ & $0.103^{* * *}$ & 0.053 \\
& $(0.000)$ & $(0.000)$ & $(0.033)$ \\
\hline NAIVE & $0.069 * * *$ & $0.073 * * *$ & $0.055 * *$ \\
& $(0.000)$ & $(0.008)$ & $(0.029)$ \\
\hline
\end{tabular}

2006

\begin{tabular}{lccc}
\hline & \multicolumn{3}{c}{ SMOKING } \\
\cline { 2 - 5 } & All & Male & Female \\
\hline DISCRATE & $0.127^{* * *}$ & $0.091^{* * *}$ & 0.029 \\
& $(0.000)$ & $(0.001)$ & $(0.271)$ \\
\hline HYPERBOL & $-0.069^{* * *}$ & $-0.055^{* *}$ & -0.013 \\
& $(0.000)$ & $(0.027)$ & $(0.591)$ \\
\hline SIGN & -0.025 & -0.033 & -0.017 \\
& $(0.189)$ & $(0.228)$ & $(0.515)$ \\
\hline PROCR & $0.1355^{* * *}$ & $0.096^{* * *}$ & 0.064 \\
& $(0.000)$ & $(0.000)$ & $(0.005)$ \\
\hline NAIVE & $0.062^{* * *}$ & $0.057^{* *}$ & 0.060 \\
& $(0.001)$ & $(0.037)$ & $(0.015)$ \\
\hline
\end{tabular}

2008

\begin{tabular}{lccc}
\hline & \multicolumn{3}{c}{ SMOKING } \\
\cline { 2 - 4 } & All & Male & Female \\
\hline DISCRATE & $0.105^{* * *}$ & $0.062^{* *}$ & 0.040 \\
& $(0.000)$ & $(0.021)$ & $(0.120)$ \\
\hline HYPERBOL & $0.042^{* *}$ & $0.052^{* *}$ & $0.056 * *$ \\
& $(0.012)$ & $(0.033)$ & $(0.014)$ \\
\hline SIGN & 0.004 & 0.003 & -0.006 \\
& $(0.842)$ & $(0.914)$ & $(0.799)$ \\
\hline PROCR & $0.095^{* * *}$ & $0.059^{* *}$ & 0.027 \\
& $(0.000)$ & $(0.011)$ & $(0.221)$ \\
\hline NAIVE & $0.042^{* *}$ & $0.048^{* *}$ & 0.031 \\
& $(0.010)$ & $(0.046)$ & $(0.166)$ \\
\hline
\end{tabular}

Pooled

\begin{tabular}{|c|c|c|c|}
\hline & & SMOKING & \\
\hline & All & Male & Female \\
\hline DISCRATE & $\begin{array}{l}0.116 * * * \\
(0.000)\end{array}$ & $\begin{array}{l}0.075 \text { *** } \\
(0.000)\end{array}$ & $\begin{array}{l}0.045 \text { *** } \\
(0.001)\end{array}$ \\
\hline HYPERBOL & $\begin{array}{l}-0.048 * * * \\
(0.000)\end{array}$ & $\begin{array}{l}-0.039 \text { *** } \\
(0.003)\end{array}$ & $\begin{array}{l}-0.015 \\
(0.219)\end{array}$ \\
\hline SIGN & $\begin{array}{l}-0.024 * * \\
(0.014)\end{array}$ & $\begin{array}{l}-0.035 * * \\
(0.015)\end{array}$ & $\begin{array}{l}-0.024 * \\
(0.078)\end{array}$ \\
\hline PROCR & $\begin{array}{l}0.124 * * * \\
(0.000)\end{array}$ & $\begin{array}{l}0.084 * * * \\
(0.000)\end{array}$ & $\begin{array}{l}0.059 * * * \\
(0.000)\end{array}$ \\
\hline NAIVE & $\begin{array}{l}0.063 \quad * * * \\
(0.000)\end{array}$ & $\begin{array}{l}0.063 * * * \\
(0.000)\end{array}$ & $\begin{array}{l}0_{0.057}^{* * *} \\
(0.000)\end{array}$ \\
\hline
\end{tabular}

Notes: The tables show the correlation coefficients of cigarette consumption with time discounting variables. Samples include nonsmokers. $\mathrm{P}$-values are in parentheses.

$*, * *, * * *$ denote statistical significance at the $10 \%, 5 \%$, and $10 \%$ levels, respectively. 
Appendix C(a): Summary statistics of SMOKING and control variables (All samples)

2005

\begin{tabular}{lrrrrr}
\hline \multicolumn{1}{c}{ Variable } & \multicolumn{1}{c}{ Obs } & \multicolumn{1}{c}{ Mean } & Std. Dev. & \multicolumn{1}{c}{ Min } & \multicolumn{1}{c}{ M ax } \\
\hline SMOKING & 2972 & 6.502 & 11.971 & 0 & 46.622 \\
SMOKING>0 & 898 & 21.517 & 12.296 & 2.739 & 46.622 \\
M ALE & 2987 & 0.470 & 0.499 & 0 & 1 \\
UNIV & 2893 & 0.204 & 0.403 & 0 & 1 \\
RISKAV & 2941 & 50.478 & 20.489 & 0 & 100 \\
INCOME & 2361 & 223.208 & 164.655 & 11.667 & 1500 \\
AGE & 2987 & 49.077 & 12.962 & 21 & 71 \\
CHILD & 2939 & 0.806 & 0.395 & 0 & 1 \\
\hline
\end{tabular}

2006

\begin{tabular}{lrrrrr}
\hline \multicolumn{1}{c}{ Variable } & Obs & \multicolumn{1}{c}{ Mean } & Std. Dev. & \multicolumn{1}{c}{ Min } & \multicolumn{1}{c}{ Max } \\
\hline SMOKING & 3746 & 6.226 & 11.679 & 0 & 46.286 \\
SMOKING $>0$ & 1066 & 21.879 & 11.697 & 2.767 & 46.286 \\
M ALE & 3763 & 0.471 & 0.499 & 0 & 1 \\
UNIV & 3632 & 0.211 & 0.408 & 0 & 1 \\
RISKAV & 3690 & 50.063 & 20.196 & 0 & 100 \\
INCOME & 3085 & 220.669 & 176.196 & 11.667 & 1700 \\
AGE & 3763 & 49.229 & 13.111 & 19 & 72 \\
CHILD & 3679 & 0.809 & 0.393 & 0 & 1 \\
\hline
\end{tabular}

2007

\begin{tabular}{lrrrrr}
\hline \multicolumn{1}{c}{ Variable } & \multicolumn{1}{c}{ Obs } & \multicolumn{1}{c}{ Mean } & Std. Dev. & Min & \multicolumn{1}{c}{ Max } \\
\hline SMOKING & 3084 & 5.873 & 11.294 & 0 & 45.619 \\
SMOKING $>0$ & 830 & 21.820 & 11.222 & 2.710 & 45.619 \\
M ALE & 3112 & 0.466 & 0.499 & 0 & 1 \\
UNIV & 3029 & 0.212 & 0.409 & 0 & 1 \\
RISKAV & 3063 & 50.250 & 20.057 & 0 & 100 \\
INCOME & 2633 & 224.453 & 179.273 & 17.500 & 3000 \\
AGE & 3112 & 50.441 & 12.849 & 20 & 73 \\
CHILD & 3069 & 0.824 & 0.381 & 0 & 1 \\
\hline
\end{tabular}

2008

\begin{tabular}{lrrrrr}
\hline \multicolumn{1}{c}{ Variable } & Obs & \multicolumn{1}{c}{ Mean } & Std. Dev. & \multicolumn{1}{c}{ Min } & \multicolumn{1}{c}{ Max } \\
\hline SMOKING & 4001 & 5.238 & 10.724 & 0 & 45.825 \\
SMOKING $>0$ & 1004 & 20.873 & 11.488 & 2.734 & 45.825 \\
M ALE & 4018 & 0.468 & 0.499 & 0 & 1 \\
UNIV & 3900 & 0.239 & 0.427 & 0 & 1 \\
RISKAV & 3960 & 49.944 & 20.112 & 0 & 100 \\
INCOME & 3529 & 225.837 & 177.167 & 7.000 & 1700 \\
AGE & 4018 & 49.981 & 13.205 & 20 & 74 \\
CHILD & 3952 & 0.808 & 0.394 & 0 & 1 \\
\hline
\end{tabular}

Pooled

\begin{tabular}{lrrrrr}
\hline \multicolumn{1}{c}{ Variable } & \multicolumn{1}{c}{ Obs } & \multicolumn{1}{c}{ Mean } & Std. Dev. & Min & \multicolumn{1}{c}{ Max } \\
\hline SMOKING & 13803 & 5.920 & 11.398 & 0 & 46.622 \\
SMOKING $>0$ & 3798 & 21.515 & 11.688 & 2.710 & 46.622 \\
M ALE & 13880 & 0.469 & 0.499 & 0 & 1 \\
UNIV & 13454 & 0.218 & 0.413 & 0 & 1 \\
RISKAV & 13654 & 50.160 & 20.203 & 0 & 100 \\
INCOME & 11608 & 223.615 & 174.910 & 7.000 & 3000 \\
AGE & 13880 & 49.686 & 13.058 & 19 & 74 \\
CHILD & 13639 & 0.811 & 0.391 & 0 & 1 \\
\hline
\end{tabular}


Appendix C(b): Summary statistics of SMOKING and control variables (male samples)

2005

\begin{tabular}{lrrrrr}
\hline \multicolumn{1}{c}{ Variable } & \multicolumn{1}{c}{ Obs } & \multicolumn{1}{c}{ Mean } & Std. Dev. & Min & \multicolumn{1}{c}{ Max } \\
\hline SMOKING & 1395 & 11.373 & 14.728 & 0 & 46.622 \\
SM OKING $>0$ & 648 & 24.483 & 12.077 & 2.753 & 46.622 \\
UNIV & 1364 & 0.297 & 0.457 & 0 & 1 \\
RISKAV & 1385 & 49.558 & 21.259 & 0 & 100 \\
INCOME & 1141 & 231.022 & 173.059 & 14 & 1500 \\
AGE & 1403 & 50.159 & 12.875 & 21 & 71 \\
CHILD & 1375 & 0.774 & 0.419 & 0 & 1 \\
\hline
\end{tabular}

2006

\begin{tabular}{lrrrrr}
\hline \multicolumn{1}{c}{ Variable } & \multicolumn{1}{c}{ Obs } & \multicolumn{1}{c}{ Mean } & Std. Dev. & Min & \multicolumn{1}{c}{ Max } \\
\hline SMOKING & 1763 & 10.937 & 14.378 & 0 & 46.286 \\
SM OKING $>0$ & 795 & 24.253 & 11.635 & 2.767 & 46.286 \\
UNIV & 1715 & 0.307 & 0.461 & 0 & 1 \\
RISKAV & 1734 & 49.156 & 21.141 & 0 & 100 \\
INCOME & 1500 & 231.259 & 187.844 & 11.667 & 1700 \\
AGE & 1774 & 50.231 & 13.045 & 19 & 72 \\
CHILD & 1729 & 0.782 & 0.413 & 0 & 1 \\
\hline
\end{tabular}

2007

\begin{tabular}{lrrrrr}
\hline \multicolumn{1}{c}{ Variable } & \multicolumn{1}{c}{ Obs } & \multicolumn{1}{c}{ Mean } & Std. Dev. & Min & \multicolumn{1}{c}{ Max } \\
\hline SMOKING & 1437 & 10.218 & 13.703 & 0 & 45.619 \\
SM OKING $>0$ & 618 & 23.760 & 10.712 & 2.797 & 45.619 \\
UNIV & 1412 & 0.311 & 0.463 & 0 & 1 \\
RISKAV & 1426 & 49.471 & 20.720 & 0 & 100 \\
INCOME & 1266 & 232.342 & 190.234 & 17.500 & 3000 \\
AGE & 1449 & 51.602 & 12.756 & 21 & 73 \\
CHILD & 1421 & 0.806 & 0.395 & 0 & 1 \\
\hline
\end{tabular}

2008

\begin{tabular}{lrrrrr}
\hline \multicolumn{1}{c}{ Variable } & Obs & \multicolumn{1}{c}{ Mean } & Std. Dev. & Min & \multicolumn{1}{c}{ Max } \\
\hline SMOKING & 1870 & 9.172 & 13.394 & 0 & 45.825 \\
SM OKING $>0$ & 734 & 23.368 & 11.193 & 2.774 & 45.825 \\
UNIV & 1825 & 0.351 & 0.477 & 0 & 1 \\
RISKAV & 1849 & 49.063 & 20.983 & 0 & 100 \\
INCOME & 1700 & 229.309 & 176.042 & 7.000 & 1700 \\
AGE & 1879 & 51.090 & 13.093 & 20 & 74 \\
CHILD & 1838 & 0.782 & 0.413 & 0 & 1 \\
\hline
\end{tabular}

Pooled

\begin{tabular}{lrrrrr}
\hline \multicolumn{1}{c}{ Variable } & \multicolumn{1}{c}{ Obs } & \multicolumn{1}{c}{ Mean } & Std. Dev. & \multicolumn{1}{c}{ Min } & \multicolumn{1}{c}{ Max } \\
\hline SM OKING & 6465 & 10.361 & 14.051 & 0 & 46.622 \\
SM OKING $>0$ & 2795 & 23.965 & 11.430 & 2.753 & 46.622 \\
UNIV & 6316 & 0.318 & 0.466 & 0 & 1 \\
RISKAV & 6394 & 49.286 & 21.024 & 0 & 100 \\
INCOME & 5607 & 230.864 & 181.893 & 7.000 & 3000 \\
AGE & 6505 & 50.769 & 12.969 & 19 & 74 \\
CHILD & 6363 & 0.786 & 0.410 & 0 & 1 \\
\hline
\end{tabular}


Appendix C(c): Summary statistics of SMOKING and control variables (female samples)

2005

\begin{tabular}{lrrrrr}
\hline \multicolumn{1}{c}{ Variable } & \multicolumn{1}{c}{ Obs } & \multicolumn{1}{c}{ Mean } & Std. Dev. & \multicolumn{1}{c}{ Min } & \multicolumn{1}{c}{ Max } \\
\hline SM OKING & 1577 & 2.193 & 6.223 & 0 & 43.060 \\
SM OKING $>0$ & 250 & 13.832 & 9.136 & 2.739 & 43.060 \\
UNIV & 1529 & 0.122 & 0.327 & 0 & 1 \\
RISKAV & 1556 & 51.298 & 19.749 & 0 & 100 \\
INCOME & 1220 & 215.900 & 156.104 & 11.667 & 1500 \\
AGE & 1584 & 48.119 & 12.969 & 21 & 71 \\
CHILD & 1564 & 0.834 & 0.372 & 0 & 1 \\
\hline
\end{tabular}

2006

\begin{tabular}{lrrrrr}
\hline \multicolumn{1}{c}{ Variable } & \multicolumn{1}{c}{ Obs } & \multicolumn{1}{c}{ Mean } & Std. Dev. & Min & \multicolumn{1}{c}{ Max } \\
\hline SMOKING & 1983 & 2.038 & 6.054 & 0 & 42.996 \\
SM OKING $>0$ & 271 & 14.916 & 8.734 & 2.777 & 42.996 \\
UNIV & 1917 & 0.125 & 0.331 & 0 & 1 \\
RISKAV & 1956 & 50.866 & 19.289 & 0 & 100 \\
INCOME & 1585 & 210.647 & 163.845 & 11.667 & 1500 \\
AGE & 1989 & 48.335 & 13.108 & 19 & 72 \\
CHILD & 1950 & 0.833 & 0.373 & 0 & 1 \\
\hline
\end{tabular}

2007

\begin{tabular}{lrrrrr}
\hline \multicolumn{1}{c}{ Variable } & \multicolumn{1}{c}{ Obs } & \multicolumn{1}{c}{ Mean } & Std. Dev. & \multicolumn{1}{c}{ Min } & \multicolumn{1}{c}{ Max } \\
\hline SMOKING & 1647 & 2.081 & 6.649 & 0 & 44.248 \\
SMOKING $>0$ & 212 & 16.166 & 10.777 & 2.710 & 44.248 \\
UNIV & 1617 & 0.126 & 0.332 & 0 & 1 \\
RISKAV & 1637 & 50.929 & 19.442 & 0 & 100 \\
INCOME & 1367 & 217.147 & 168.228 & 17.500 & 1700 \\
AGE & 1663 & 49.428 & 12.848 & 20 & 73 \\
CHILD & 1648 & 0.839 & 0.368 & 0 & 1 \\
\hline
\end{tabular}

2008

\begin{tabular}{lrrrrr}
\hline \multicolumn{1}{c}{ Variable } & \multicolumn{1}{c}{ Obs } & \multicolumn{1}{c}{ Mean } & Std. Dev. & Min & \multicolumn{1}{c}{ Max } \\
\hline SM OKING & 2131 & 1.785 & 5.748 & 0 & 43.201 \\
SM OKING $>0$ & 270 & 14.092 & 9.355 & 2.734 & 43.201 \\
UNIV & 2075 & 0.142 & 0.349 & 0 & 1 \\
RISKAV & 2111 & 50.715 & 19.288 & 0 & 100 \\
INCOME & 1829 & 222.610 & 178.193 & 10.000 & 1700 \\
AGE & 2139 & 49.006 & 13.229 & 20 & 74 \\
CHILD & 2114 & 0.832 & 0.374 & 0 & 1 \\
\hline
\end{tabular}

Pooled

\begin{tabular}{lrrrrr}
\hline \multicolumn{1}{c}{ Variable } & \multicolumn{1}{c}{ Obs } & \multicolumn{1}{c}{ Mean } & Std. Dev. & \multicolumn{1}{c}{ Min } & \multicolumn{1}{c}{ Max } \\
\hline SMOKING & 7338 & 2.008 & 6.144 & 0 & 44.248 \\
SMOKING $>0$ & 1003 & 14.688 & 9.487 & 2.710 & 44.248 \\
UNIV & 7138 & 0.129 & 0.336 & 0 & 1 \\
RISKAV & 7260 & 50.929 & 19.420 & 0 & 100 \\
INCOME & 6001 & 216.842 & 167.856 & 10.000 & 1700 \\
AGE & 7375 & 48.730 & 13.062 & 19 & 74 \\
CHILD & 7276 & 0.834 & 0.372 & 0 & 1 \\
\hline
\end{tabular}


2005

\begin{tabular}{lccl}
\hline & \multicolumn{3}{c}{ SMOKING } \\
\cline { 2 - 4 } & All & Male & Female \\
\hline MALE & 0.383 *** & & \\
& $(0.000)$ & $-0.127 * * *$ & $-0.052 * *$ \\
& -0.012 & $(0.000)$ & $(0.044)$ \\
\hline UNIV & $(0.506)$ & $-0.137 * * *$ & -0.041 \\
& $-0.109 * * *$ & $(0.000)$ & $(0.107)$ \\
\hline RISKAV & $(0.000)$ & $0.060 * *$ & $-0.051 *$ \\
& $0.041 * *$ & $(0.043)$ & $(0.078)$ \\
\hline INCOME & $(0.047)$ & $-0.060 * *$ & $-0.124 * * *$ \\
& $-0.039 * *$ & $(0.025)$ & $(0.000)$ \\
\hline AGE & $(0.033)$ & $-(0.023)$ & $-(0.047) *$ \\
& $-(0.055) * * *$ & $(0.393)$ & $(0.067)$ \\
\hline CHILD & $(0.003)$ & & \\
& & &
\end{tabular}

2007

\begin{tabular}{lcll}
\hline & \multicolumn{3}{c}{ SMOKING } \\
\cline { 2 - 4 } & All & Male & Female \\
\hline MALE & $0.360 * * *$ & & \\
& $(0.000)$ & & \\
\hline UNIV & -0.019 & $-0.130 * * *$ & $-0.065 * * *$ \\
& $(0.305)$ & $(0.000)$ & $(0.009)$ \\
\hline RISKAV & $-0.091 * * *$ & $-0.102 * * *$ & $-0.059 * *$ \\
& $(0.000)$ & $(0.000)$ & $(0.017)$ \\
\hline INCOME & -0.003 & -0.010 & -0.037 \\
& $(0.879)$ & $(0.718)$ & $(0.175)$ \\
\hline AGE & $-0.037 * *$ & $-0.066 * *$ & $-0.097 * * *$ \\
& $(0.040)$ & $(0.013)$ & $(0.000)$ \\
\hline CHILD & $-(0.029)$ & $(0.002)$ & $-(0.047) *$ \\
& $(0.114)$ & $(0.940)$ & $(0.056)$ \\
\hline
\end{tabular}

2006

\begin{tabular}{lccc}
\hline & \multicolumn{3}{c}{ SMOKING } \\
\cline { 2 - 4 } & $0.380 * * *$ & Male & Female \\
\hline MALE & $(0.000)$ & & \\
\hline UNIV & -0.021 & $-0.136 * * *$ & $-0.075 * * *$ \\
& $(0.202)$ & $(0.000)$ & $(0.001)$ \\
\hline RISKAV & $-0.100 * * *$ & $-0.112 * * *$ & $-0.059 * * *$ \\
& $(0.000)$ & $(0.000)$ & $(0.009)$ \\
\hline INCOME & -0.001 & -0.016 & $-0.047 *$ \\
& $(0.967)$ & $(0.536)$ & $(0.061)$ \\
\hline AGE & $-0.033 * *$ & $-0.052 * *$ & $-0.112 * * *$ \\
& $(0.044)$ & $(0.029)$ & $(0.000)$ \\
\hline CHILD & $-(0.043) * * *$ & $-(0.008)$ & $-(0.050) * *$ \\
& $(0.009)$ & $(0.734)$ & $(0.028)$ \\
\hline
\end{tabular}

2008

\begin{tabular}{lccc}
\hline & \multicolumn{3}{c}{ SMOKING } \\
\cline { 2 - 4 } & All & Male & Female \\
\hline M ALE & $0.344^{* * *}$ & & \\
& $(0.000)$ & $-0.118 * * *$ & $-0.072 * * *$ \\
UNIV & -0.010 & $(0.000)$ & $(0.001)$ \\
\hline RISKAV & $(0.528)$ & $-0.099 * * *$ & $-0.087 * * *$ \\
& $-0.099 * * *$ & $(0.000)$ & $(0.000)$ \\
\hline INCOME & $(0.000)$ & -0.016 & -0.035 \\
& -0.013 & $(0.515)$ & $(0.140)$ \\
\hline AGE & $(0.446)$ & $-0.042 * *$ & $-0.096 * * *$ \\
& -0.025 & $(0.071)$ & $(0.000)$ \\
\hline CHILD & $(0.122)$ & $(0.038)$ & $-(0.017)$ \\
& $-(0.003)$ & $(0.102)$ & $(0.442)$ \\
\hline
\end{tabular}

Pooled

\begin{tabular}{|c|c|c|c|}
\hline & \multicolumn{3}{|c|}{ SMOKING } \\
\hline & All & Male & Female \\
\hline MALE & $\begin{array}{l}0.366 \text { *** } \\
(0.000)\end{array}$ & & \\
\hline UNIV & $\begin{array}{l}-0.017 \quad * * \\
(0.050)\end{array}$ & $\begin{array}{l}-0.130 \quad * * * \\
(0.000)\end{array}$ & $\begin{array}{l}-0.067 \quad * * * \\
(0.000)\end{array}$ \\
\hline RISKAV & $\begin{array}{l}-0.099 * * * \\
(0.000)\end{array}$ & $\begin{array}{l}-0.111 * * * \\
(0.000)\end{array}$ & $\begin{array}{l}-0.062 \quad * * * \\
(0.000)\end{array}$ \\
\hline INCOME & $\begin{array}{c}0.003 \\
(0.719)\end{array}$ & $\begin{array}{c}0.001 \\
(0.927)\end{array}$ & $\begin{array}{l}-0.0422^{* * *} \\
(0.001)\end{array}$ \\
\hline$\overline{\mathrm{AGE}}$ & $\begin{array}{l}-0.034 * * * \\
(0.000)\end{array}$ & $\begin{array}{l}-0.056 * * * \\
(0.000)\end{array}$ & $\begin{array}{l}-0.107 \quad * * * \\
(0.000)\end{array}$ \\
\hline CHILD & $\begin{array}{c}-(0.032) * * * \\
(0.000)\end{array}$ & $\begin{array}{l}(0.003) \\
(0.820)\end{array}$ & $\begin{array}{c}-(0.039) * * * \\
(0.001)\end{array}$ \\
\hline
\end{tabular}

Notes: The tables show the correlation coefficients of cigarette consumption with control variables. Samples include nonsmokers.

$\mathrm{P}$-values are in parentheses.

$*, * *, * * *$ denote statistical significance at the $10 \%, 5 \%$, and $10 \%$ levels, respectively. 
Appendix E: Tax hikes, smoking moderation, and increasing rates of tax revenue

Model (1): The marginal effect of tax $=\mathbf{- 0 . 4 1 6}$

\begin{tabular}{l|c|ccc} 
& before tax hikes & \multicolumn{3}{c}{ after tax hikes } \\
\hline Cigarette price per pack & JPY 300 & JPY 500 & JPY 700 & JPY 1000 \\
(USD 2.80) & (USD 4.67) & (USD 6.53) & (USD 9.33) \\
\hline \multirow{2}{*}{$\begin{array}{l}\text { TAX per cigarette } \\
\text { JPY 0 }\end{array}$} & $\begin{array}{c}\text { JPY 10 } \\
\text { (USD 0.09) }\end{array}$ & $\begin{array}{c}\text { JPY 20 } \\
\text { (USD 0.19) }\end{array}$ & $\begin{array}{c}\text { JPY 35 } \\
\text { (USD 0.33) }\end{array}$ \\
\hline Averaged cigarette consumption & 20.873 & 18.880 & 14.725 & 13.956 \\
Smoking rates & $25.1 \%$ & $22.4 \%$ & $22.4 \%$ & $15.6 \%$ \\
Smoking cessation rates for smokers & $0.0 \%$ & $10.7 \%$ & $10.7 \%$ & $37.8 \%$ \\
\hline Increasing rates of revenues & $0.0 \%$ & $73.2 \%$ & $107.2 \%$ & $107.9 \%$
\end{tabular}

Model (2): The marginal effect of tax $=\mathbf{- 0 . 4 2 3}$

\begin{tabular}{l|c|ccc} 
& before tax hikes & \multicolumn{3}{c}{ after tax hikes } \\
\hline Cigarette price per pack & $\begin{array}{c}\text { JPY 300 } \\
\text { (USD 2.80) }\end{array}$ & $\begin{array}{c}\text { JPY 500 } \\
\text { (USD 4.67) }\end{array}$ & $\begin{array}{c}\text { JPY 700 } \\
\text { (USD 6.53) }\end{array}$ & $\begin{array}{c}\text { JPY 1000 } \\
\text { (USD 9.33) }\end{array}$ \\
\hline \multirow{2}{*}{$\Delta$ TAX per cigarette } & JPY 0 & JPY 10 & JPY 20 & JPY 35 \\
& (USD 0) & (USD 0.09) & (USD 0.19) & (USD 0.33) \\
\hline Averaged cigarette consumption & 20.873 & 18.807 & 14.579 & 13.701 \\
Smoking rates & $25.1 \%$ & $22.4 \%$ & $22.4 \%$ & $15.6 \%$ \\
Smoking cessation rates for smokers & $0.0 \%$ & $10.7 \%$ & $10.7 \%$ & $37.8 \%$ \\
\hline Increasing rates of revenues & $0.0 \%$ & $72.6 \%$ & $105.1 \%$ & $104.1 \%$
\end{tabular}

Model (3): The marginal effect of tax $=\mathbf{- 0 . 3 1 5}$

\begin{tabular}{l|c|ccc} 
& \multicolumn{3}{c}{ after tax hikes } \\
\hline Cigarette price per pack & $\begin{array}{c}\text { JPY 300 } \\
\text { (USD 2.80) }\end{array}$ & $\begin{array}{c}\text { JPY 500 } \\
\text { (USD 4.67) }\end{array}$ & $\begin{array}{c}\text { JPY 700 } \\
\text { (USD 6.53) }\end{array}$ & $\begin{array}{c}\text { JPY 1000 } \\
\text { (USD 9.33) }\end{array}$ \\
\hline \multirow{2}{*}{$\Delta$ TAX per cigarette } & JPY 0 & JPY 10 & JPY 20 & JPY 35 \\
& (USD 0) & (USD 0.09) & (USD 0.19) & (USD 0.33) \\
\hline Averaged cigarette consumption & 20.873 & 19.890 & 16.745 & 17.491 \\
Smoking rates & $25.1 \%$ & $22.4 \%$ & $22.4 \%$ & $15.6 \%$ \\
Smoking cessation rates for smokers & $0.0 \%$ & $10.7 \%$ & $10.7 \%$ & $37.8 \%$ \\
\hline Increasing rates of revenues & $0.0 \%$ & $82.5 \%$ & $135.6 \%$ & $160.5 \%$
\end{tabular}

Notes: This tabels show the predicted smoking status and increasing rates of government's revenues responding to tax hikes by JPY 10, 20, and 35 (around USD 0.09, 0.19, and 0.33) per cigarette. Estimated coefficients of TAX in model (1), (2), and (3) for full samples are used for the predictions, respectively. The marginal effects are measured around mean values of smokers in 2008. The rows of "Cigarette price per pack" show the hypothetical prices per 20-cigarette pack after tax hikes calculated by (20* $\triangle \mathrm{TAX}$ per cigarette). The rows of " $\triangle \mathrm{TAX}$ per cigarette" show the increased rates of tax per cigarette. The rows of "Averaged cigarette consumption", "Smoking rates", and "Smoking cessation rates for smokers" show the resulting status of cigarette consumption after tax hikes. The rows of "Increasing rates of revenues" show the net increasing rates of government's revenues by hiking cigarette tax. 
Appendix F: Tax hikes and the increasing rates of tax revenue

Panel (A): The marginal effect of TAX= -0.416 (Model (1))

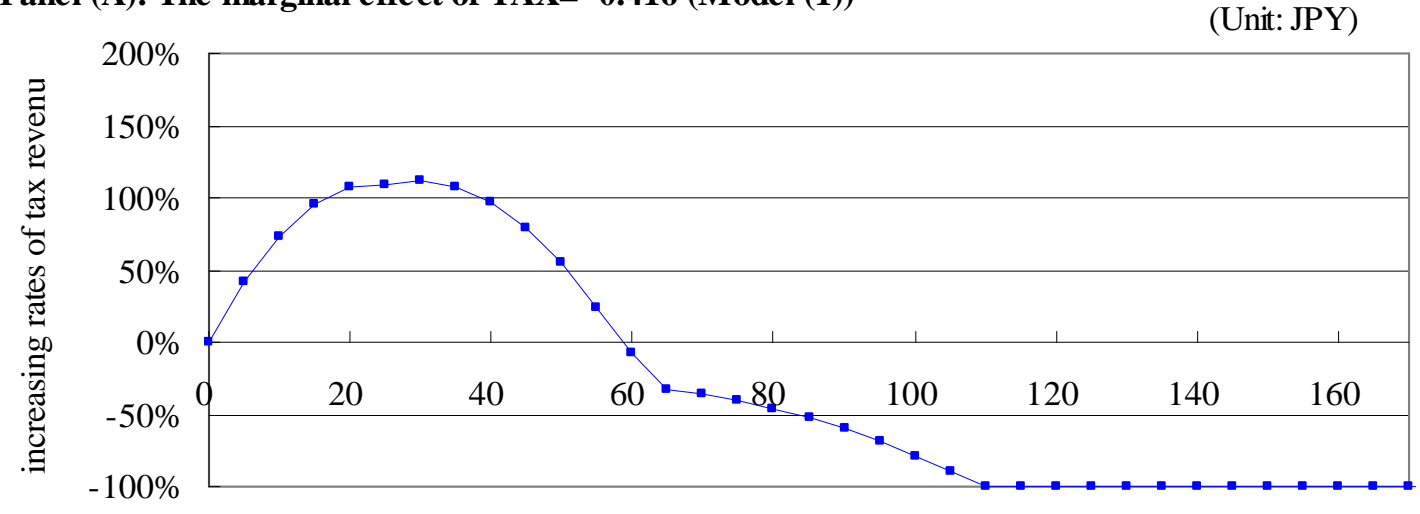

$\triangle \mathrm{TAX}$

Panel (B): The marginal effect of TAX= -0.423 $($ Model $(2))$

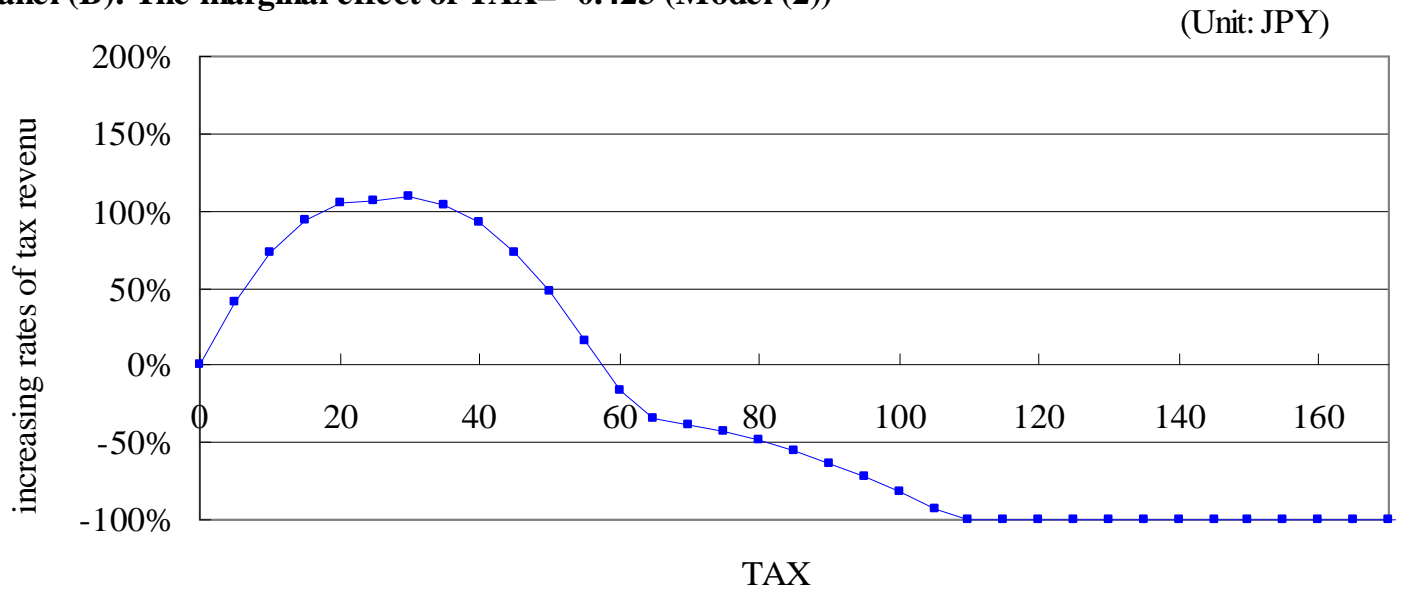

Panel (C): The marginal effect of TAX= -0.315 $($ Model $(3))$

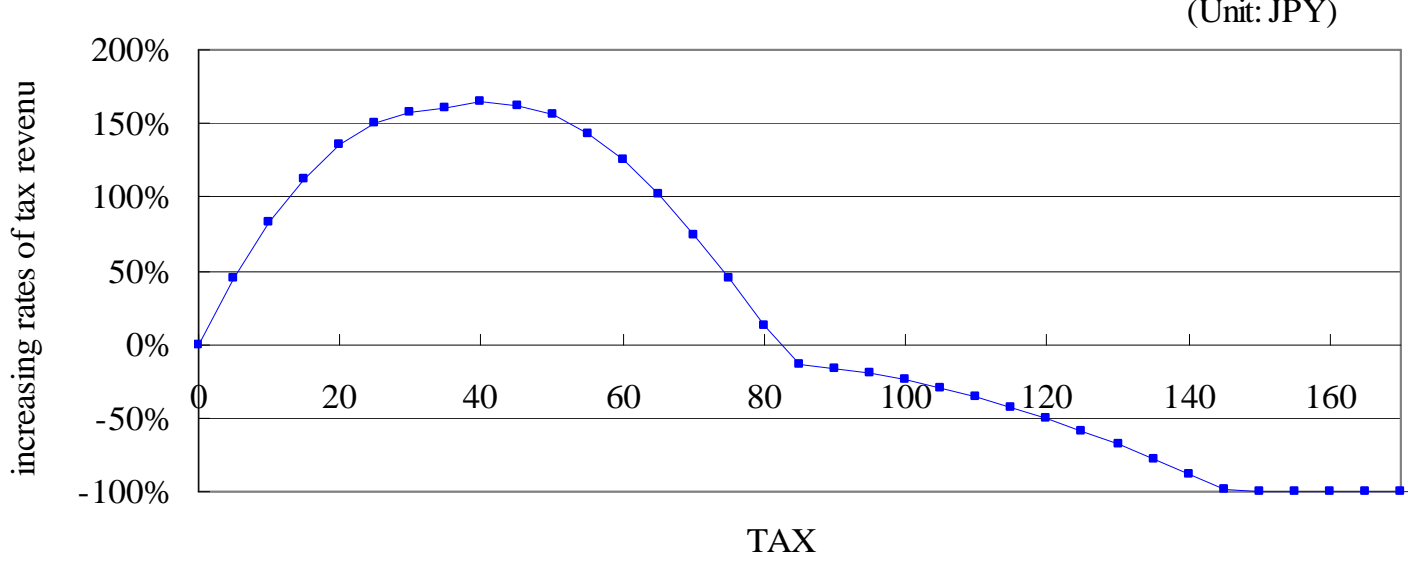

Notes: This figures show the predicted increasing rates of government's revenues responding to tax hikes. The horizonal axes indicate the increased rates of tax per cigarette. The vertical axes indicate the net increasing rates of government's revenues by hiking cigarette tax in JPY terms. The estimated coefficients of TAX in model (1), (2), and (3) for full samples are used for the predictions, respectively. The marginal effects are measured around mean values of smokers in 2008. 